\title{
Tracking strategic developments for conferring xylose utilization/fermentation by Saccharomyces cerevisiae
}

\author{
Shalley Sharma* and Anju Arora
}

\begin{abstract}
Purpose: Efficient ethanol production through lignocellulosic biomass hydrolysates could solve energy crisis as it is economically sustainable and ecofriendly. Saccharomyces cerevisiae is the work horse for lignocellulosic bioethanol production at industrial level. But its inability to ferment and utilize xylose limits the overall efficacy of the process.

Method: Data for the review was selected using different sources, such as Biofuels digest, Statista, International energy agency (IEA). Google scholar was used as a search engine to search literature for yeast metabolic engineering approaches. Keywords used were metabolic engineering of yeast for bioethanol production from lignocellulosic biomass.

Result: Through these approaches, interconnected pathways can be targeted randomly. Moreover, the improved strains genetic makeup can help us understand the mechanisms involved for this purpose.

Conclusion: This review discusses all possible approaches for metabolic engineering of yeast. These approaches may reveal unknown hidden mechanisms and construct ways for the researchers to produce novel and modified strains.
\end{abstract}

Keywords: Saccharomyces cerevisiae, Metabolic engineering, Random approaches, Adaptation, Protoplast fusion

\section{Introduction}

Energy demand is rapidly growing worldwide due to population explosion and industrial revolution and enhanced dependence and utilization of natural energy resources. Conventional resources of fuels like petroleum oil, coal, and gas are the major contributors of energy. Consequently, greenhouse gas emission has disrupted the natural atmosphere of earth (Robak and Balcerek 2018). Increasing energy demand cannot be met by the depleting fossil fuel reserves. A study conducted in 2013 on peak oil suggested that peak oil, the theorized time point at which petroleum extraction reaches its maximum and then starts declining, would occur probably before 2030, and it also indicated significant chances of occurrence before 2020

\footnotetext{
* Correspondence: shalleyss@gmail.com

Division of Microbiology, ICAR-Indian Agricultural Research Institute, New Delhi 110012, India
}

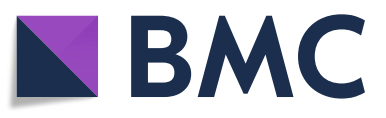

(Miller and Sorrell 2014). Urgency to reduce reliance on conventional sources of energy persists, urging utilization of renewable sources of energy for economic benefit. Another major concern is the environmental impact resulting from the consumption of fossil fuels. Therefore, alternate sources like bioethanol and biodiesel are currently trending worldwide.

Currently, major producers of bioethanol are the USA and Brazil. In 2018, USA ranked first in generating 16.1 billion gallons of biofuel, and Brazil was the second largest producer with 8 billion gallon production (Fig. 1). India stood at seventh position after the European Union, China, Canada, and Thailand with 330 million gallons of bioethanol production in 2018. India stands third in the world for the import of petroleum products. Crude oil import has rapidly increased from 99.40 million ton in 2006 fiscal year to 228.6 MT in 2019 fiscal year (Biofuels Digest, Statista 2019). Among the

(c) The Author(s). 2020 Open Access This article is licensed under a Creative Commons Attribution 4.0 International License, which permits use, sharing, adaptation, distribution and reproduction in any medium or format, as long as you give appropriate credit to the original author(s) and the source, provide a link to the Creative Commons licence, and indicate if changes were made. The images or other third party material in this article are included in the article's Creative Commons licence, unless indicated otherwise in a credit line to the material. If material is not included in the article's Creative Commons licence and your intended use is not permitted by statutory regulation or exceeds the permitted use, you will need to obtain permission directly from the copyright holder. To view a copy of this licence, visit http://creativecommons.org/licenses/by/4.0/. 


\section{Ethanol (Billion Gallon Litres)}

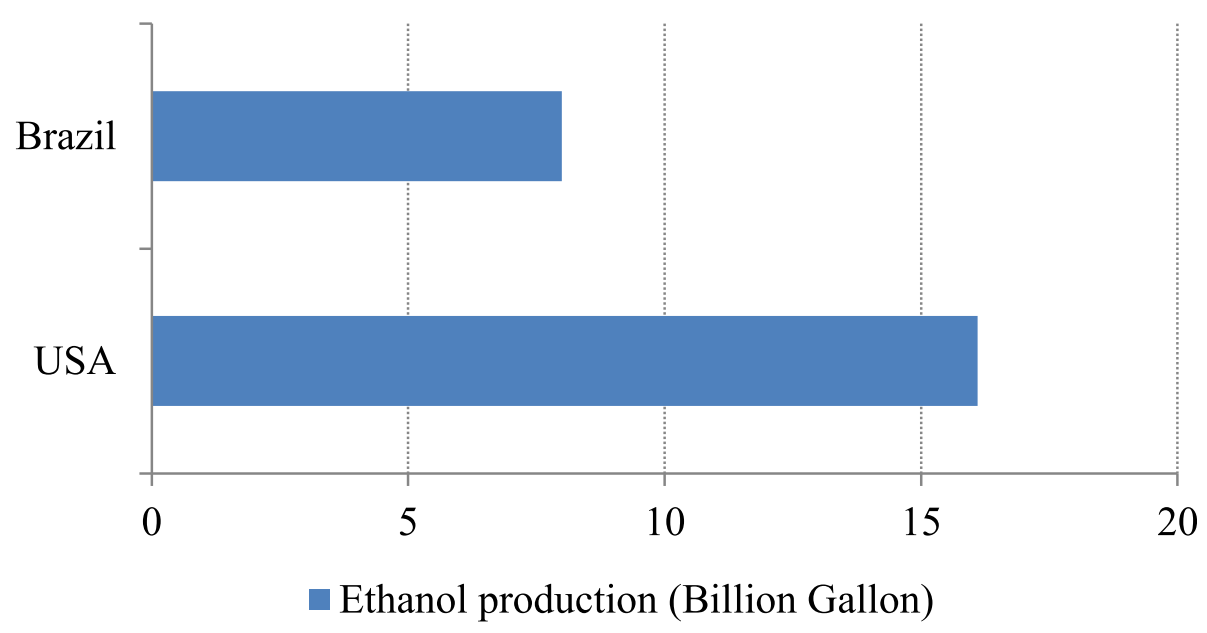

Fig. 1 Ethanol production by the USA and Brazil in billion gallon liters

petroleum products imported, $49 \%$ counts for transportation. This could be replaced by bioethanol in the coming years to improve energy utilization scenario nationally.

Biofuels are defined as those fuels which are derived from organic matter. These can be broadly categorized as primary and secondary biofuels. Primary biofuels are used in their crude form, such as fuel wood. It is used for cooking, generating heat, and electricity. However, transport fuels are considered as secondary biofuels, and these include bioethanol and biodiesel. Biofuels, specifically bioethanol and biodiesel, have become the primary need in today's society as for transportation; dependency on fossil fuel reserves is tremendously increasing. Globally, utilization of energy resources is crucial for shaping the growth and economy of budding nations. Consequently, due to depletion of fossil fuels and increasing power demands along with environmental pollution, the focus of research has shifted towards renewable and environment friendly fuel resources. Utilizing renewable resources for biofuel production serves striking solutions in reducing the green-house gas emissions, thereby lowering the impact on environment. This also reduces dependency on foreign oils, resolves energy security issues, empowers economies, and improves the sustainability of transportation system globally (Tabah et al. 2017).

Bioethanol produced from the edible sources is considered as first generation biofuel. However, this raised the issue of food versus fuel. Therefore, as a substitute, focus shifted towards utilization of cellulosic bioethanol. This second generation bioethanol depends on agricultural residues (such as stover, bagasse, deoiled seed residues, stems, straw, and leaves) which serve as sources of lignocellulosic biomass. Lignocellulosic materials are cheap renewable resources, available in large quantities. Lignocellulosic wastes extracted from energy crops and residues constitute the abundant sources of renewable biomass. Energy security concerns seem resolvable through utilization of lignocellulosic biomass, as it resolves food vs fuel debate and is environmental friendly (Millati et al. 2002). Extensive research is being carried out for the fractionation of this biomass into its constituents to make the process cost effective and to make sugars, like glucose and xylose, available for $2 \mathrm{G}$ bioethanol production (Selim et al. 2018). Technology has now advanced from $2 \mathrm{G}$ ethanol to $3 G$ and $4 \mathrm{G}$ as well. Third generation biofuel is derived from algal biomass; fourth generation biofuels utilize genetically modified algae for enhanced biofuel production (Abdullah et al. 2019). However, producing biofuels like bioethanol from lignocellulosic biomass is an entirely different scenario presenting different set of challenges because of its chemical composition and recalcitrance.

There are other approaches to enhance energy recovery from lignocellulosic biomass such as bio-refining, pretreatment, and waste recycling. Primarily, biorefining is a promising technique to utilize crop residues, reducing the greenhouse gas emission and producing bio-based products. However, biomass cannot be utilized in its native form and requires pretreatment prior to its conversion. There are various procedures for pretreatment of the lignocellulosic biomass, such as biological pretreatment, chemical, and mechanical pretreatments.

Nutrient recycling is another approach to enhance economic and environmental sustainability in bioethanol 
production. Collection of biomass ash is one way of nutrient recycling in biofuel production (Ai et al. 2019; Elsayed et al. 2018; Elsayed et al. 2019).

This review focuses on the limitations of the second generation bioethanol production and various possible technologies used for ethanol production. In general, it discusses the genetic engineering as well as random approaches used for ethanol production from lignocellulosic biomass.

\section{Lignocellulosic biomass for 2G biofuels}

Lignocellulosic biomass comprises cellulose, hemicellulose, and lignin. The LCB (lignocellulosic biomass) derived biofuel, known as $2 \mathrm{G}$ biofuel, has several advantages.

\section{Composition of LCB}

Components of lignocellulose vary inside the cell walls of LCB (Sarkar et al. 2012), and the proportion of cellulose, hemicellulose, and lignin differs with the type of plant and tissue (Table 1). For instance, cellulose content in dried hardwoods is $40-45 \%$ by weight with $24-40 \%$ hemicellulose and $18-25 \%$ lignin. However, these ratios differ for corn stover, which possess these components as $27-48 \%, 13-17 \%$, and $14-31 \%$, respectively.

Most abundant component, cellulose is a polymer of D-glucose units linked through $\beta-1,4$ linkages. Due to massive hydrogen bonding in its structure, its hydrolysis becomes a tedious task. On the contrary, hemicellulose consists of different types of sugars such as xylose, arabinose, and glucose. Majorly, it consists of pentoses which cannot be fermented easily unlike glucose. Lignin, on the other hand, is a phenolic polymer which possesses $\mathrm{CO}-\mathrm{C}$ ether bonds throughout. This makes its deconstruction a tedious task (Wang et al. 2014).

Lignocellulosic biomass appears promising in energy sector, but its efficient utilization and conversion to ethanol is a difficult task due to non-utilization of xylose by the fermenting micro-organisms such as yeast and bacteria (Chu and Lee 2007). These microorganisms do not possess metabolic machinery for efficient xylose fermentation to produce ethanol. However, for the costeffective production of ethanol, both sugars need to be fermented.

\section{Xylose metabolism}

Xylose metabolism follows two-step oxido-reductive pathway. Xylose is converted to xylitol by the xylose reductase (XR), which is NADPH-dependent (Webb and Lee 1990). Xylitol then produces xylulose by the enzyme xylitol dehydrogenase (XDH) which is NAD-dependent. Xylulose is catalyzed by xylulokinase (XKS) to produce xylulose-5-phosphate. Finally, xylulose-5-phosphate, an intermediate for pentose phosphate pathway (PPP), enters PPP and glycolysis eventually, yielding ethanol after anaerobic process of fermentation.

There is an alternative route for the production of xylulose from xylose. This substitutional pathway exists in some bacteria and fungi, wherein xylose isomerase catalyzes the reaction and produces xylulose directly from xylose (Mishra and Singh 1993). Xylitol accumulation is thereby inhibited. Pichia stipitis has been studied extensively for its xylose metabolizing properties. An illustration of xylose metabolic pathway is presented in Fig. 2.

\section{Influence of pentose phosphate pathway enzymes on xylose metabolism}

Pentose phosphate pathway (PPP) starts with the xylulose-5-P entry, and further intrinsic metabolic activities occur through this route (Kobayashi et al. 2018). PPP can be categorized in two phases-oxidative and non-oxidative. Xylose metabolizing enzyme, such as xylose reductase (XR), requires NADPH (reduced nicotinamide adenosine dinucleotide phosphate) as a cofactor for its proper functioning and effective conversion of xylose to xylitol. In oxidative pathway, NADPH is produced which replenishes the co-factor requirements of XR (Hector et al. 2011). This process plays a vital role in xylose metabolism and thereby ethanol production.

Non-oxidative pathway involves four enzymes. Genes for these are as follows:

a) transaldolase (TAL1)

b) transketolase (TKL1)

c) ribose-5-phosphate ketolisomerase (RPK1)

d) D-ribulose-5-phosphate 3 epimerase (RPE1)

TAL1 catalyzes the conversion of glyceraldehyde 3phosphate and sedoheptulose-7-phosphate to produce erythrose-4-phosphate and fructose-6-phosphate. TKL1 catalyzes aldoses (ribose-5-phosphate, erythrose-4-P, and

Table 1 Carbohydrate content in various agricultural wastes (lignocellulosic biomass) (\%)

\begin{tabular}{lllllll}
\hline Biomass & Glucose & Xylose & Mannose & Galactose & Arabinose & Reference \\
\hline Rice straw & $41-43.4$ & $14.8-20.2$ & 1.8 & 0.4 & $2.7-4.5$ & Karimi et al. (2006) \\
Wheat straw & $38.8 \pm 0.5$ & $22.2 \pm 0.3$ & $1.7 \pm 0.2$ & $2.7 \pm 0.1$ & $4.7 \pm 0.1$ & Erdei et al. (2010) \\
Corn straw & 39 & 14.8 & 0.3 & 0.8 & 3.2 & Lee (1997) \\
Bagasse & 38.1 & 23.3 & - & 1.1 & 2.5 & Lee (1997) \\
\hline
\end{tabular}




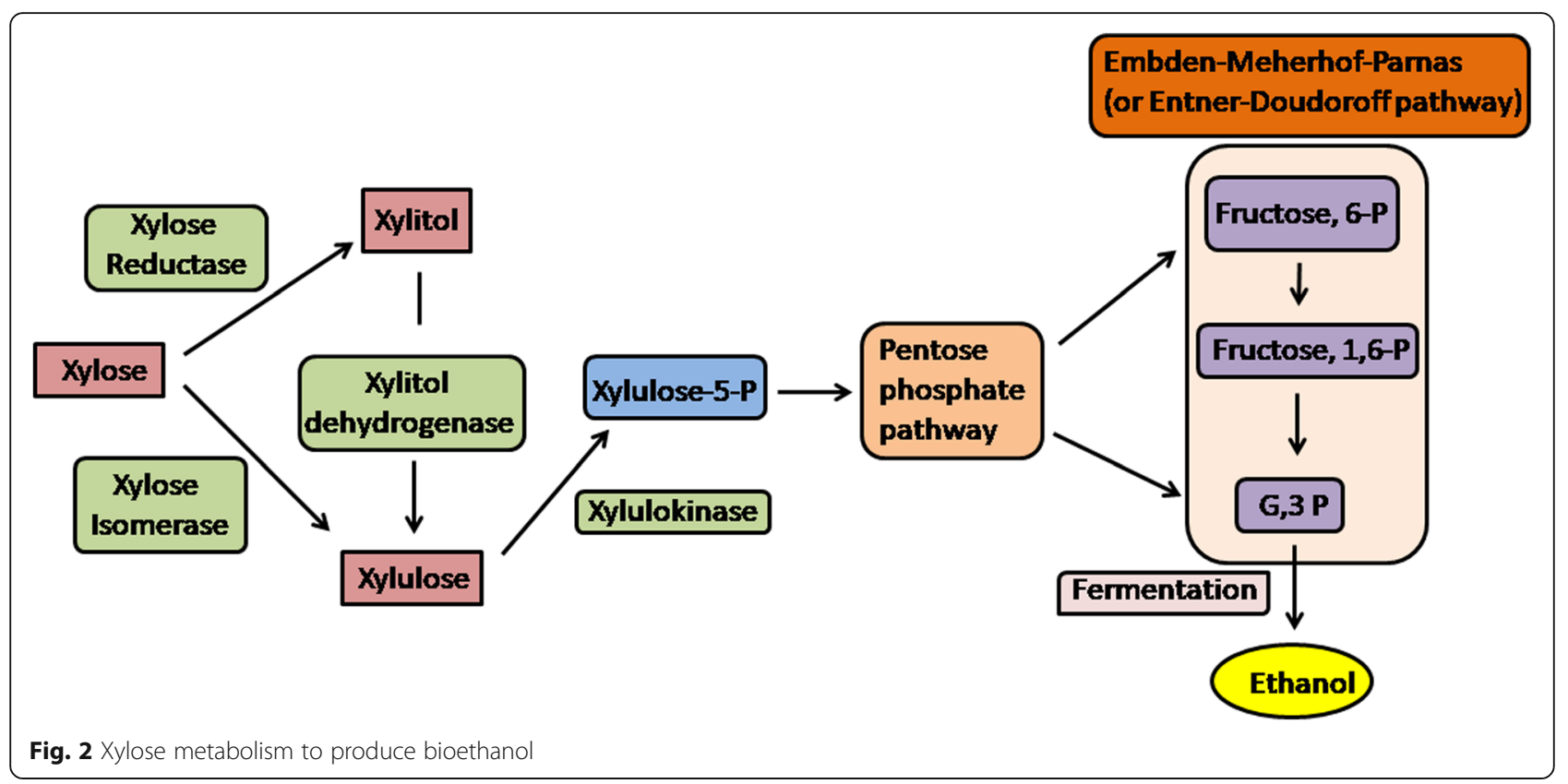

G-3-P) into ketoses (xylulose-5-phosphate, fructose-6-P, and sedoheptulose-7-phosphate) (Lindqvist et al. 1992). RKI1 and RPE1 catalyze conversions of ribulose-5-P (Miosga and Zimmermann 1996). All the four enzymes are able to catalyze these processes reciprocally (Fig. 3).

PPP enzymes are significantly linked with each other, making the whole process complicated for metabolic engineering purposes (Kobayashi et al. 2017). Although ethanol titers are increased by overexpression of these genes in recombinant $S$. cerevisiae (Karhumaa et al. 2005; Karhumaa et al., 2007a; Li et al. 2014), but the best combination of these genes for expression in $S$. cerevisiae has not been demonstrated yet and is yet to be studied in detail (Karhumaa et al., 2007b; Matsushika et al. 2012; Li et al. 2014). Besides overexpression of PPP genes, ethanol production was also observed to be improved with the deletion/disruption of a putative phosphatase PHO13 gene (Karhumaa et al. 2005; Li et al. 2014; Kim et al. 2015; Xu et al. 2016). This clearly demonstrates that there are several other factors involved in the xylose metabolism among which PPP enzymes play a major role.

\section{Xylose transport}

For efficient co-utilization and fermentation of mixed sugars (glucose + xylose) pertaining to LCB hydrolysates, insights into the xylose transport are mandatory apart from the in-depth knowledge of xylose metabolic pathways. For this, native pentose metabolizing yeasts like Pachysolen tannophilus, Scheffersomyces shehatae, and Scheffersomyces stipitis and Kluyveromyces sp. have been studied. All these strains can ferment xylose to ethanol but at lower rates as compared to glucose fermentation rates (Jeffries 1985). This accounts for their low ethanol tolerance (Maleszka and Schneider, 1982a) and xylitol accumulation. Besides, xylose utilization can occur only after its transport into the cell, so transporters play a significant role in xylose metabolism.

Since $S$. cerevisiae is the preferred microbe for bioethanol production from LCB, transporters have been extensively studied for this yeast for conferring effective xylose consumption. It lacks dedicated transporters for xylose uptake. However, it possesses 18 transporters for hexose sugars, classified as Hxt1-Hxt17 and one galactose permease (Gal2), Snf3p, and Rgt2p which transport hexoses inside the cell (Anjos et al. 2013). Nevertheless, only seven transporters are involved in glucose transport, Hxt1-Hxt7 and Gal2. These transporters have been classified into three categories on the basis of their glucose affinity as follows:

i. High-affinity transporters: Hxt6, Hxt7, Gal 2

ii. Mid-affinity transporters: Hxt2, Hxt4, Hxt5

iii. Low-affinity transporters: Hxt1 and Hxt3 (Moysés et al. 2016; Hara et al. 2017)

The high-affinity transporters exhibit higher competitive behavior for xylose transport through glucose repression.

There are two ways of xylose transport-facilitated diffusion and active diffusion. The latter mechanism requires metabolic energy, and sugar uptake is carried out against a concentration gradient. This mechanism can further be classified depending upon the type of metabolic energy preference, like direct energization, chemoosmotic, or group translocation. On the contrary, 


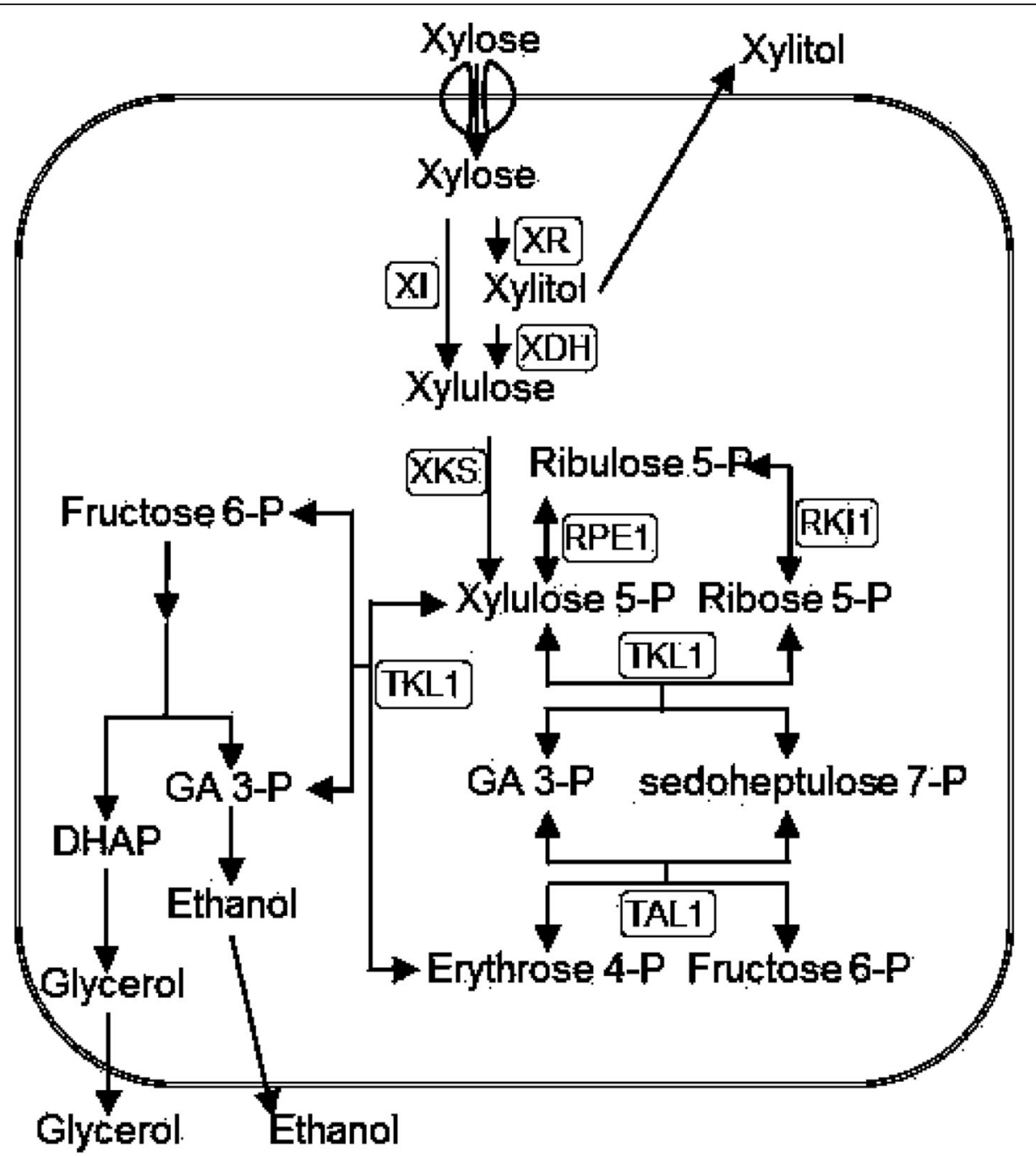

Fig. 3 Role of PPP enzymes in xylose metabolism \{Source: Kobayashi et al. 2017 \}

facilitated diffusion mechanism possesses no such energy requirements. But both the systems require carrier proteins to transport sugars across the cell membranes and hence become specific to the substrate type/sugars.

As these are substrate specific, the transport systems are competitively inhibited by their analogs or other sugars. Other than these, the chemo-osmotic proton symport-based transport systems, a type of active transport mechanism, also exist, but they are $\mathrm{pH}$-dependent and work only under desired pH conditions (McMillan 1993). For xylose uptake, there are two import systems: low-affinity, high capacity facilitated diffusion mechanism for transportation of both sugars (glucose and xylose); and proton symport system specifically for xylose uptake (high affinity) (Lucas and Van Uden 1986; Kilian and Van Uden 1988; Does and Bisson 1989). Former mechanism is adopted by $S$. cerevisiae, Candida shehatae, and Schizosaccharomyces pombe. Hxt transporters usually implement transport through facilitated diffusion. However, proton symport mechanism is followed by pentose metabolizing yeast like $C$. intermedia, Kluyveromyces marxianus, S. stipitis, and C. shehatae. It is generally preferred mode of transport during stresses.

Thus, the major concern has been the co-utilization of mixed sugars during LCB fermentation for bioethanol production. Several approaches involving transporters have been investigated for enhancing co-fermentation. These may be categorized as follows:

i. Mutagenesis of endogenous hexose transporters for xylose transport (Li et al. 2016)

ii. Heterologous expression of xylose transporters (Belisa et al. 2015) 
iii. Heterologous expression of xylose metabolizing genes for alleviation of glucose repression (de Figueiredo et al. 2015)

iv. Combination of above two approaches ( $\mathrm{Li}$ et al. 2016)

Although various efforts have been done to pursue this research, but each study has a diverse approach. Therefore, additional studies for the creation of an improved strain with enhanced ability to uptake both sugars are mandatory.

\section{Micro-organisms for lignocellulosic biomass fermentation S. cerevisiae: an organism of choice for industrial fermentation}

Saccharomyces cerevisiae is broadly used for 1st generation bioethanol production and is considered most suitable for $2 \mathrm{G}$ bioethanol production. This is because of its fermentation properties as it is the best hexose fermenter. Moreover, it can withstand harsh conditions, required at the industrial level. It has high ethanol tolerance and osmo-tolerance and can survive fair concentrations of inhibitors present in the hydrolysates. Micro-organisms other than S. cerevisiae, like bacteria like Zymomonas mobilis and recombinant Escherichia coli, are capable of diverse sugar utilization. However, for industrial fermentation processes, S. cerevisiae is favored. This is due to its stress tolerance properties, GRAS (generally regarded as safe) status, and resistance to bacteriophage infection, making it superior to bacterial fermentation (Dien et al. 2003; Moyses et al. 2016; Albergaria and Arneborg 2016).

Several efforts have been exercised to improve $S$. cerevisiae strains for mixed sugar fermentation. One such effort was successfully undertaken by Nancy Ho and coworkers working at Purdue University (Ho et al. 1998). S. cerevisiae strain 1400 was genetically engineered by cloning $\mathrm{XR}, \mathrm{XDH}$, and $\mathrm{XKS}$ genes along with their respective glycolytic promoters. Hence, a good hexose fermenting S. cerevisiae was improved to ferment xylose as well during co-fermentation. They also showed that this strain converts most of the sugars into ethanol rather than byproduct accumulation which is the case in other strategies (Tantirungkij et al. 1993; Kötter et al. 1990; Walfridsson et al. 1997). Moreover, the cloned genes were not affected by glucose in the medium and alleviated catabolite repression. This strain could efficiently ferment both sugars (xylose and glucose) without a lag phase.

\section{Xylose metabolism in S. cerevisiae}

Xylose metabolism starts with the uptake of this sugar. As discussed earlier, xylose is transported through the cells via two mechanisms, active and facilitated diffusion.
S. cerevisiae imports xylose through facilitated diffusion. However, this transport mechanism has higher glucose specificity than towards xylose. Therefore, this yeast becomes inefficient to metabolize xylose. Although there are homologs of xylose metabolizing genes in this yeast, but the functional metabolic pathway does not exist. Examples of such genes are GRE3, YPR1, SOR1, YJR096W (xylose reductase), YDL246C (xylitol dehydrogenase), YLR070C, and YKS1 (xylulokinase). Moreover, metabolism does not begin immediately after its uptake, and a lag phase is generally observed wherein metabolic enzymes are produced to start metabolism (Gong et al. 1981; Lucas and Van Uden 1986; Jeffries 1983; Toivari et al. 2004).

Overexpression of these native genes in S. cerevisiae enhanced the fermentation process. Xylitol was accumulated as a byproduct. This ascertained the presence of xylose metabolic pathway in hexose fermenting Saccharomyces. For instance, when GRE3 and ScXYL2 were overexpressed, yeast strain could grow on xylose under aerobic conditions, even though glucose was also present. But xylitol accumulation was too high. This could be due to the lower activity of $\mathrm{XDH}$ and specificity of Gre3p towards NADPH which is a reductase. XRs are unable to supply $\mathrm{NAD}^{+}$, which work as co-factors for $\mathrm{XDH}$. Therefore, anaerobically feasibility of this reaction is impossible due to limiting $\mathrm{NAD}^{+}$which requires oxygen. This results in non-utilization of xylose anaerobically in the presence of glucose. Hence, redox imbalance occurs due to the affinity of Gre3p towards NADPH.

\section{Limitations}

\section{Xylose transport}

Earlier, absence of xylose metabolizing genetic machinery was blamed for inefficiency in xylose utilization by $S$. cerevisiae. Various strategies were employed for conferring this ability in yeast, such as, by producing xylulose directly from xylose through catalysis by glucose isomerase and then its subsequent fermentation to ethanol (Chandel et al. 2011). Later, with the emphasis on xylose transport, it was revealed that xylose is imported with the aid of hexose transporters, and therefore, its uptake rate is slower (Van Vleet and Jeffries 2009). It is also evident that $S$. cerevisiae has xylose transport system and other genes responsible for xylose metabolism (Gárdonyi et al. 2003). But it cannot ferment it to ethanol efficiently because xylose fermentation is an oxygenic process while glucose fermentation occurs under oxygen limiting conditions. Moreover, under oxygenic conditions, ethanol produced gets oxidized and lowers the overall efficiency of the process.

Numerous efforts are being carried out to alter the strain genetically so that it can utilize xylose and ferment it to ethanol. Apparently, cellobiose hydrolysis pathway 
was heterologously expressed in S. cerevisiae. It consisted of a cellodextrin transporter gene (cdt-1) and an intracellular $\beta$-glucosidase gene (gh1-1), derived from Neurospora crassa. This allowed cellobiose hydrolysis in the yeast, and co-fermentation of xylose and cellobiose was observed (Wei et al. 2015; Chen et al. 2018). This process is more beneficial because co-utilization of these sugars could enhance the ethanol productivity when compared with glucose and xylose co-fermentation.

Moreover, different strategies employed for constructing a modified strain of $S$. cerevisiae with xylose metabolizing abilities have dealt with several issues. For instance, heterologous expression of XR, XDH genes in this yeast has been a failure in enhancing ethanol production due to co-factor/redox imbalance.

\section{Co-factor requirements of xylose metabolizing enzymes}

Since XR and XDH have specificities for NADPH and NAD respectively, and NADH regeneration solicits oxygenic environment. However, glucose fermentation requires anaerobic conditions. Therefore, during the cofermentation, redox imbalance is created. To address this, strains with altered co-factor affinities have been constructed. Generally, the modifications are carried out in three ways:

i. By altering XRs affinity for $\mathrm{NADH}$ with respect to $\mathrm{NADPH}$,

ii. By enhancing specificity of XDHs towards NADPH with respect to NAD, and

iii. By alteration of affinities of both enzymes.
For instance, there are two yeast species Candida parapsilosis and Spathaspora passalidarum, in which XRs have higher affinity for NADH than NADPH. $S$. passalidarum is a better xylose fermenter under oxygen limiting systems (Hou 2012). Several such efforts have been carried out. Some are presented in Table 2, wherein mutagenesis was engaged for alteration of specificities of these co-factors.

XRs have IPKS (Ile-Pro-Lys-Ser) motif. 2'-Phosphate of NADPH interacts with the lysine residue of the motif making it more specific for NADPH (Lee et al. 2008). Therefore, mutations are carried out in XRs more frequently to alter its specificity for NADPH. Reduced specificity for NADPH will lower its requirement during the metabolic pathway; thereby, the process could simultaneously workout with glucose fermentation for mixed substrate fermentation during lignocellulosic fermentation for bioethanol production.

\section{Xylitol accumulation}

In recombinant strains of $S$. cerevisiae, xylitol is produced as a major byproduct. It is due to the higher production of NADPH as compared to NADH during the initial assimilation steps of xylose. When XYL1 (xylose reductase) is overexpressed in S. cerevisiae, xylitol accumulation is observed (Kim et al., 2013a). Therefore, proportional increase in XYL2 (xylitol dehydrogenase) with respect to XYL1 reduces xylitol accumulation and enhances ethanol production (Jin and Jeffries 2004). However, NADPH is also mandatory for bioethanol production. This was proved by studies carried out by

Table 2 Alteration of specificities of XRs and XDHs of different yeast strains

\begin{tabular}{|c|c|c|c|}
\hline Yeast & Mutation & Purpose & Reference \\
\hline \multicolumn{4}{|c|}{ XR mutants } \\
\hline \multirow[t]{5}{*}{ C. tenuis } & K274M & NADPH to NADH preference & Petschacher and Nidetzky (2005) \\
\hline & K274R & & \\
\hline & S275A & & \\
\hline & $\mathrm{N} 276 \mathrm{D}$ & & \\
\hline & $\mathrm{R} 280 \mathrm{H}$ & & \\
\hline \multirow[t]{5}{*}{ S. stipitis } & K341R/N343D & NADPH to NADH preference & Dmytruk et al. (2008) \\
\hline & E223A & Strict NADPH dependence & Khattab et al. (2011) \\
\hline & $E 223 D$ & & \\
\hline & $\mathrm{S} 271 \mathrm{~A}$ & & \\
\hline & K270M & NADPH to NADH preference & Kostrzynska et al. (1998) \\
\hline \multicolumn{4}{|c|}{ XDH mutants } \\
\hline \multirow[t]{5}{*}{ S. stipitis } & $1208 R$ & NAD to NADP preference & Watanabe et al. (2005) \\
\hline & F209S & & \\
\hline & N211R & & \\
\hline & D270G & NADP preference & Metzger and Hollenberg (1995) \\
\hline & D270G/D210G & NAD to NADP preference & \\
\hline
\end{tabular}


Jeppsson et al. (2003). P. stipitis produces very low levels of xylitol but is not used for commercial bioethanol production purposes because of lower xylose fermentation rates. Overexpression of xylose metabolizing genes from $P$. stipitis to $S$. cerevisiae also does not solve the problem of xylitol accumulation indicating the significant role of other intrinsic factors responsible for low xylitol accumulation in P. stipitis (Jeppsson et al. 2003).

To reduce xylitol production during co-fermentation, several approaches can be adopted. These include, addition of extra electron acceptor to the fermentation medium, altering ammonium assimilation pathways, redirecting carbon fluxes through phosphoketolase pathway, relating furaldehyde reduction to xylose metabolic pathway, and changing the affinities of XR and XDH for $\mathrm{NADH}$ and NADPH (Roca et al. 2003; Sonderegger et al. 2004; Almeida et al. 2011).These have resulted in lower accumulation of xylitol with enhanced ethanol production.

\section{Other factors affecting xylose metabolism}

On commercial level, temperature is considered a major factor for fermentation as cooling system may elevate the cost of infrastructure. Additionally, it can impact gene expression of yeast strains used for industrial fermentations (Ismail et al. 2013). Likewise, higher temperatures affect PPP enzymes during xylose fermentation (Osiro et al. 2019).

As discussed earlier, xylose is not metabolized if glucose is present, and this "glucose repression" creates hindrance in the co-fermentation of both sugars. Glucose repression refers to the inability of the yeast cells to utilize xylose, when glucose is present in the same medium. Once glucose is completely utilized, then $x y-$ lose uptake starts. This has also been revealed recently that xylose is not sensed extracellularly by this yeast as a fermentative substrate. Presence of xylose initiates the same response in yeast as the low concentrations of glucose which is non-fermentative. Therefore, xylose paradox could be resolved by integrating metabolic engineering with sugar sensing and signalomics of the yeast strains (Osiro et al. 2019).

\section{Non-conventional native pentose fermenting yeasts}

There are non-conventional yeast strains capable of $x y-$ lose fermentation; these have been identified and studied in detail. These yeast species are able to metabolize xylose and produce ethanol as well through fermentation. Examples of such yeast are Pichia, Pachysolen, Brettanomyces, Candida, Clavispora, Kluyveromyces, and Schizosaccharophora, etc. Among these, Pichia stipitis is considered as the best native pentose fermenting yeast with high ethanol titers through xylose fermentation (McMillan 1993; Sharma et al. 2016). Other strains like
Candida shehatae and Pachysolen tannophilus are also good fermenters of xylose. These strains have been investigated meticulously, and it has been established that some of these can produce ethanol through xylose fermentation even under anaerobic environments (Skoog et al. 1990; Fonseca et al. 2007).

However, there are certain constraints faced in using these strains for commercial purposes. These include low ethanol tolerance, low osmotic tolerance, low sugar tolerance, and low inhibitor tolerance. Since these yeast species cannot tolerate higher concentrations of ethanol, resultant ethanol productivity is lowered. Moreover, their rate of fermentation of xylose is lower as compared to that of glucose by $S$. cerevisiae. In addition to this, they possess low tolerance for hydrolysate inhibitors generated during the pretreatment of LCB. Inhibitors have been categorized majorly as phenolics, furans (HMF and furfural), and weak acids (Parajó et al. 1996).

There are certain confinements associated with all the fermenting micro-organism involved in co-fermentation of mixed sugars (glucose and xylose). These hinder the overall process and limit the production of ethanol. Although efforts are being done to reduce these constraints, but still accuracy has not been achieved.

\section{Scope for improvement}

Complicated inter-connected metabolic pathways hinder the development of improved strains; therefore, metabolic engineering strategies should be exercised.

\section{Metabolic engineering}

Metabolic engineering came into existence in 1991 (Bailey 1991). As the name suggests, it encompasses all those engineering and modification tacts which are linked to the metabolism of organism. It is the study of metabolic pathway involving rewiring of one or more paths so as to yield a desired metabolic product such as bioethanol (Stephanopoulos 2007; Lee 2012). This strategy can be utilized to enhance xylose utilization and fermentation by studying its metabolism. Xylose metabolism has been comprehensively investigated in pentose fermenting yeasts, and the regulatory genes/enzymes have been identified. These xylose metabolizing genes were expressed in $S$. cerevisiae, exhibiting $0.51 \mathrm{~g} \mathrm{~g}^{-1}$ theoretical yield through xylose metabolism and fermentation. However, maximal productivities were lower (Ostergaard et al. 2000).

Different approaches of metabolic engineering include rational metabolic engineering, inverse metabolic engineering, and evolutionary engineering (Nevoigt 2008). Description and advantages of these strategies have been given in Table 3. 
Table 3 Metabolic engineering approaches for strain improvement (Source: Nevoigt 2008)

\begin{tabular}{lll}
\hline Strategy & Description & Advantage(s) \\
\hline $\begin{array}{l}\text { Rational metabolic } \\
\text { engineering }\end{array}$ & $\begin{array}{l}\text { Engineering metabolic pathways based on available } \\
\text { information }\end{array}$ & $\begin{array}{l}\text { Known genetic modifications can be transferred to other } \\
\text { strains }\end{array}$ \\
$\begin{array}{l}\text { Inverse metabolic } \\
\text { engineering }\end{array}$ & $\begin{array}{l}\text { Identification of genetic basis for a particular phenotype } \\
\text { and transferring it to the host for generation of a similar } \\
\text { phenotype }\end{array}$ & $\begin{array}{l}\text { Prior information of genes is not required; it can reveal } \\
\text { novel targets for modifications }\end{array}$ \\
$\begin{array}{l}\text { Random engineering strategies } \\
\text { Evolutionary engineering }\end{array}$ & $\begin{array}{l}\text { Dependent on random mutations; requires screening } \\
\text { techniques for selection of desired mutants }\end{array}$ & $\begin{array}{l}\text { Prior information of genes is not required; multiple genes } \\
\text { can be targeted }\end{array}$ \\
$\begin{array}{l}\text { Transposon mutagenesis } \\
\text { and gene overexpression } \\
\text { libraries }\end{array}$ & $\begin{array}{l}\text { Random mutations in single genes; requires screening } \\
\text { techniques }\end{array}$ & $\begin{array}{l}\text { Prior information of genes is not required; it can reveal } \\
\text { novel targets for modifications }\end{array}$ \\
$\begin{array}{l}\text { Global transcription } \\
\text { machinery engineering }\end{array}$ & $\begin{array}{l}\text { Mutations in the basal transcription factors, gene } \\
\text { transcription is rewired; requires screening methods }\end{array}$ & $\begin{array}{l}\text { Prior information of genes is not required; multiple genes } \\
\text { can be targeted; reprogrammed genes can be transferred to } \\
\text { other strains }\end{array}$ \\
\hline
\end{tabular}

${ }^{a}$ Special cases of evolutionary engineering

\section{Genetic engineering}

As $P$. stipitis is widely known for its xylose metabolism, genes from this yeast are transferred to $S$. cerevisiae for improving its mixed sugar fermentation potential. Initially, through genetic engineering, XYL1, XYL2, and XKS from Pichia, were expressed in Saccharomyces. Other way, XI from bacteria was also heterologously expressed in this yeast. This enhanced ethanol production but with lower fermentation rates unlike glucose. But none of these engineering efforts resulted in a significantly improved strain. These strategies relied on the existing knowledge of metabolism and genes involved in it. However, there are several other factors, genes, enzymes, and pathways associated with xylose metabolism which complicate its fermentation. As a result, such strategies require configuration to construct an improved strain. Later, ratios of the above mentioned genes were optimized for higher ethanol productivities (Eliasson et al. 2001; Matsushika and Sawayama 2008). In addition, dedicated xylose transporters were also transferred to industrial yeasts, and alteration in the specificities of coenzymes required by $\mathrm{XR}$ and $\mathrm{XDH}$ was also performed through genetic engineering approaches (Matsushika and Sawayama 2008; Matsushika et al. 2008).

To maximize the utilization of xylose by yeast strains, especially $S$. cerevisiae, various genetic engineering efforts have been carried out. However, the resultant strains are unable to produce ethanol on the industrial levels. This might be due to the complex nature of the yeast metabolic regulations (Selim et al. 2018). S. cerevisiae is considered for genetic manipulation as it has the most studied genome, and various engineering tools are present to manipulate its pathways for the purpose. Moreover, pentose fermenting yeast strains are unable to ferment both hexoses and pentoses simultaneously. Due to this, introduction of new pathways in the genetically modified strains is considered as the best mechanism to overcome this issue.
With the advent of pentose fermenting yeast strains, interest in the biochemical pathways for the metabolism of xylose emerged (Maleszka and Schneider, 1982b; Slininger et al. 1982). Thereby, biocatalyst engineering appeared as a platform to produce bioethanol through yeast sp. To illustrate, enzymes responsible for the eight reactions of xylose metabolism to ethanol were identified in yeast for functional expression in S. cerevisiae. This was followed by a combinatorial expression analysis so as to screen the rate limiting steps (Latimer and Dueber 2017). Through this metabolic evolution, different ways were invented to adjust for the disconnection between the actual biochemical patterns and the expected ones.

Major focus is generally paid over the modification of $S$. cerevisiae yeast. For xylose fermentation, $P$. stipitis has also been manipulated. Through metabolic engineering PPP, sugar transport, terminal steps of fermentation, glycolysis, and the interconnection between fermentation and respiration could be manipulated. Since $S$. cerevisiae does not possess metabolic pathway for xylose assimilation, genes from $P$. stipitis are expressed in it for better xylose metabolism. However, this resulted in very low levels of xylose assimilation. Although xylose metabolism has been studied, deeper insights of non-conventional yeasts fermenting xylose could enhance the engineering strategies (Jeffries 2009). Theoretically, ethanol yields could be enhanced by $S$. cerevisiae through xylose assimilation by harboring xylose reductase, xylitol dehydrogenase, and xylulokinase. But the precision has still not been achieved so as to determine which approach is responsible to enhance the fermentative properties of the yeast (Karhumaa et al., 2007a). Moreover, deeper knowledge of the interconnected pathways is required to modify yeast strains to effectively utilize lignocellulosic biomass for fermentation (Jin et al. 2004). Therefore, non-conventional xylose fermenting yeast like $P$. stipitis has attracted much attention to study biochemical, 
physiological, and genetic regulations for improving fermentation traits of $S$. cerevisiae.

With the overexpression of xylose reductases and xylitol dehydrogenases (XYL1 and XYL2) from P. stipitis to $S$. cerevisiae, significant ethanol yields were not enhanced due to xylitol accumulation. This occurred due to the dual cofactor preferences of XYL1 and XYL2 of $P$. stipitis and an imbalance in the activities of oxidative and non-oxidative PPP (Kötter and Ciracy 1993). Similarly, engineering of PPP enzymes into yeast also led to the improvements in ethanol titers. Such as overexpression of TAL1 and TKL1 in Saccharomyces cerevisiae ( $S$. cerevisiae) at $30{ }^{\circ} \mathrm{C}$ and overexpression of all PPP genes at $36{ }^{\circ} \mathrm{C}$ resulted in the highest ethanol productivities (Kobayashi et al. 2017).

Transketolase (TKL1) and Transaldolase (TAL1) are PPP enzymes; overexpression of TKL1 from Pichia strain to Saccharomyces strain results in reduced growth rate of the modified strain on xylose containing minimal medium (Metzger and Hollenberg 1994). It was also observed that when TKL1 from Pichia was overexpressed in Saccharomyces along with XYL1 and XYL2, the recombinant strain showed faster growth rate than the strain expressing XYL1 and XYL2 alone (Walfridsson et al. 1995). Nonetheless, the growth rate of the transformant was lower than that of the parent strain due to the plasmid burden carrying three genes (XYL1, XYL2, and TAL1) (Bao et al. 1997; Meinander et al. 1999).

To determine the ability of $S$. cerevisiae to assimilate and metabolize xylose, xylose reductases were expressed in this yeast system. This led to the xylose assimilation under oxygenic conditions along with the production of xylitol when there was no other sugar substrate in the medium (Kötter et al. 1990; Amore et al. 1991). On the contrary, overexpression of XYL2 leads to the accumulation of xylulose, suggesting XKS activity inhibits the xylose assimilation and utilization (Jin and Jeffries 2003).

As discussed earlier, first successful recombinant strain of $S$. cerevisiae was constructed by Ho et al. The recombinant strain was efficient in xylose and mixed sugar fermentation. Ho et al. used XR and XDH from P. stipitis. Whereas when endogenous XKS gene was overexpressed, it was unable to grow on xylulose (RodriguezPeña et al. 1998). Although when all the endogenous genes were overexpressed, ethanol fermentation was efficiently carried out (Toivari et al. 2001). This infers that regulated expression of XKS is mandatory for efficient ethanol production. Several such efforts have been carried out since then for creating a modified and improved strain (Karhumaa et al. 2007a; Ni et al. 2007; Matsushika and Sawayama 2008; Matsushika et al. 2009; Van Vleet and Jeffries 2009).

Recent advances in genetic engineering tools such as the advent of CRISPR-Cas (Clustered Regularly Interspaced
Short Palindromic Repeat) technology has been a milestone for strain development (Cong et al. 2013). CRISPRassociated nucleases, Cas 9, have been used to create sequence specific double strand breaks in vitro. This technique has been used for reverse engineering in $S$. cerevisiae to confer xylose fermentation (Bao et al. 2014; Jansen et al. 2017). Genetic changes occurring in the strains improved through evolutionary engineering have been studied, and the same genes are targeted in the host organisms to produce single nucleotide mutations through CRISPR-Cas9 molecules.

As discussed earlier, S. cerevisiae does not possess xylose specific transporters; it cannot properly consume xylose present in the lignocellulosic biomass. It exports xylose through glucose specific transporters. Therefore, there is tremendous scope of improvement in ethanol production through heterologous expression of xylose specific transporters in this yeast. A lot of research has diverted towards transporter engineering.

Heterologous transfer of transporter genes has also facilitated xylose metabolism during co-fermentation processes. For instance, cryptic hexose transporter (chimeric Hxt11/2 transporter), engineered into a $D$ xylose transporter, resulted in the co-fermentation of mixed sugars (Shin et al. 2017). As stated in the earlier section, HXT transporters are responsible for glucose uptake in S. cerevisiae. The two mechanisms of sugar transport have been discussed, facilitated diffusion, and proton symport mechanism. Former mechanism is more promising as it does not require much energy for sugar uptake. A transporter from $C$. intermedia following the xylose/glucose proton symport mechanism was transported into $S$. cerevisiae. This enhanced xylose consumption, but the $\mathrm{Km}$ was 10 folds lower than for glucose (Leandro et al. 2006). Other two transporters, GSX1 and GXF1, enhance glucose uptake ten times higher than glucose. When gxf1 was engineered in $S$. cerevisiae, there was not much effect on the growth rate of this yeast at higher xylose concentrations. However, at lower concentrations of xylose, it promoted the growth of the yeast strain (Runquist et al. 2009).

Later, researchers found out that $P$. stipitis being a native pentose fermenting yeast possesses high-affinity $x y-$ lose transporters and low uptake system for glucose/ xylose shared uptake (Hahn-Hägerdal et al. 2001). Moreover, it was found out that $S$. cerevisiae exploits highaffinity xylose transporters for xylose uptake rather than innate low-affinity transporter specific for glucose uptake. Hence, under glucose limiting conditions, both the sugars are utilized together (Meinander and Hagerdal 1997). Since Sut1-3 are the main glucose transporters in P. stipitis, expressions in S. cerevisiae lead to increment in the utilization of both sugars (Katahira et al. 2008). 
Sut1 and Sut3 have higher affinity for xylose than the corresponding glucose transporters of $S$. cerevisiae.

Later, it was also found out that apart from yeast and bacteria, filamentous fungi, Aspergillus nidulans and Trichoderma reesei, also possess xylose transporters. $x$ trD, a xylose transporter from $A$. nidulans, was introduced into $S$. cerevisiae, and it was observed that this strain could grow on a wide range of sugars such as xylose, galactose, glucose, and mannose, with highest affinity towards xylose (Colabardini and Ries 2014).

Advantage of this strategy is the targeted approach and thus its precision and accuracy. It does not pose any undesirable adverse effects on the strains. Genetic engineering is precise in targeting a particular gene of interest involved in the metabolism. However, this approach relies on the limited database of metabolic pathways leaving few targets for improvements.

\section{Evolutionary engineering}

Evolutionary engineering includes all the experimental methods for strain improvement which involve random mutagenesis rather than targeted approach, eventually followed by selection of cells with desired traits (Sauer 2001). This strategy includes several cycles of random mutations and sequential selection, which create genetic mutations involving the desired ones (Sauer and Schlattner 2004) and can be very effective in strain improvement (Overkamp et al. 2002; Sonderegger and Sauer 2003; Shi et al. 2014). Furthermore, this approach has also enhanced the stress tolerance levels of $S$. cerevisiae (Martín et al. 2007). Major advantage of this technique is no prior information of the genome is required, and random mutations are produced containing the desired ones.

In a study by Kim et al., 2013b, xylose toxicity was removed through evolutionary engineering of $S$. cerevisiae. Xylose toxicity was evident after the strain was grown on xylose concentrations above $10 \mathrm{~g} \mathrm{~L}^{-1}$. Third subculture of the strain showed significant improvement in the growth rate and ethanol production. Attfield and Bell (2006) adapted native strain of $S$. cerevisiae to grow solely on xylose as the sole carbon source with $<6 \mathrm{~h}$ doubling time. Similarly, evolutionary engineering can also be used to investigate stress resistance properties of yeast. Koppram et al. (2012) demonstrated inhibitor tolerance in S. cerevisiae TMB3400. After 97 generations, maximum specific growth rate was enhanced to $0.33 \mathrm{~h}^{-1}$. Improved strains displayed better tolerance to inhibitors upon growth in spruce hydrolysates. In another study, evolutionary engineering was employed to increase resistance to hydroxymethyl furfural and furfural by serially transferring the $S$. cerevisiae cultures to medium containing increasing concentrations of these inhibitors (Liu et al. 2005).

\section{Evolutionary genetic approach}

This approach is engaged for recombinant strains to enhance their ethanol productivities and make them stress tolerant. Recombinant strain is subjected to varying stresses, to which it may adapt with time. Adapted best strain is then screened out through selection techniques. As an example, a diploid recombinant strain was mutagenized, and the strain growing on xylose was selected (Demeke et al. 2013). Further, their genomes were shuffled, and selection was done on D-xylose pre-treated spruce hydrolysate. Best cultures were selected and subjected to evolutionary adaptations. Strain at the last stage of xylose fermentation was considered as the most superior yeast for xylose fermentation.

\section{Mutagenesis}

Mutagenesis is either site directed or random, where site directed mutagenesis is a targeted approach, whereas random mutations are not locus specific. Targeted mutations could be used to alter the specificities of cofactors (Watanabe et al. 2005, Watanabe et al. 2007; Matsushika and Sawayama 2008; Matsushika et al. 2008) while random mutations could be easily introduced through approaches like adaptation and protoplast fusion. Moreover, UV-induced mutations and EMS (ethyl methane sulfonate) induced mutations also create such random mutations. Additionally, recombinant strains can also be mutagenized to increase ethanol titers in comparison to the parent strains (Tantirungkij et al. 1994; Sonderegger and Sauer 2003). An outline of different engineering strategies has been provided in Fig. 4.

Chemical mutagenesis using EMS was used to improve ethanol production abilities of $S$. cerevisiae. Six mutated colonies grew on $10 \%$ ethanol concentration, and one of them produced $17.3 \%$ more bioethanol than the parent strain (Mobini-Dehkordi et al. 2008). Acetic acid tolerance in S. cerevisiae was enhanced using UV mutagenesis by Zheng et al. (2011).

\section{Other strategies}

Strategies other than targeting direct gene involved in xylose metabolism involve pursuing the effect of PPP genes. As mentioned in the "Influence of pentose phosphate pathway enzymes on xylose metabolism" section, there are four major enzymes involved in PPP. Heterologous overexpression of their genes in S. cerevisiae has augmented xylose fermentation process (Jin et al. 2005). Bio-prospecting such genes linked to xylose metabolism indirectly could further enhance the efficacy of the process.

\section{Protoplast fusion and genome shuffling}

Another significant improvement strategy is protoplast fusion. It involves genome shuffling between micro- 


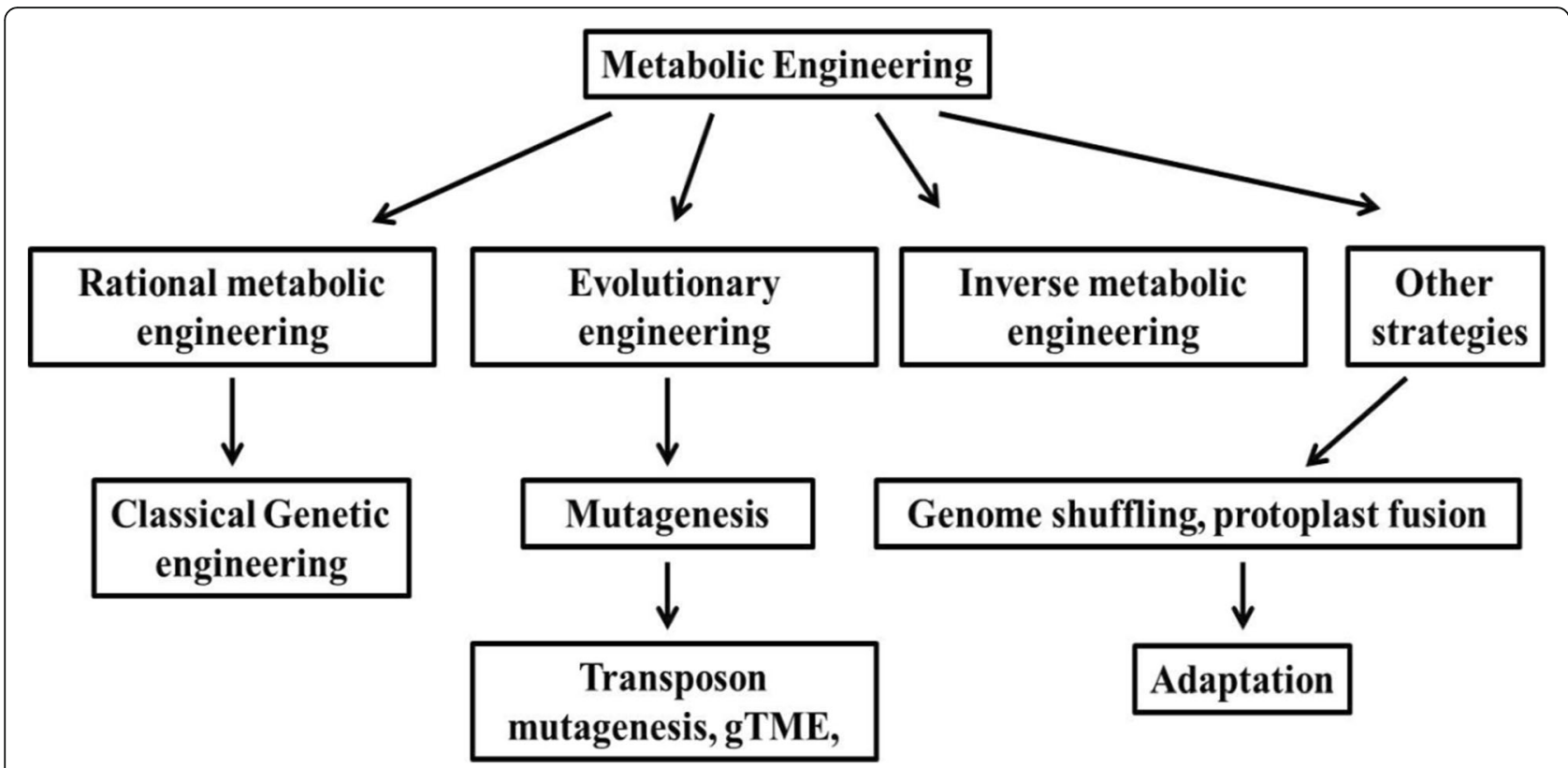

Fig. 4 An outline of several metabolic engineering approaches for strain improvement

organisms. This is generally carried out for such strains which do not possess any genetic information (Heluane et al. 1993). It works on the basis of creation of random mutations through genome transfer. To add to its advantages, larger segments of DNA can also be transferred unlike classical genetic engineering approaches which rely on vectors for gene transfer. It also generates a number of fusants which possess desired metabolic traits. For fusion of two strains, a fusogenic reagent is required to bring them in close proximity with each other. It can done via PEG (polyethylene glycol) or though electroporation as well. Fusion can be applied to develop a strain with mixed sugar fermentation potential by shuffling genomes of hexose and xylose fermenting yeasts (Heluane et al. 1993; Lin et al. 2005; Pasha et al. 2007). Also, xylose fermenting strains can be obtained as a result of DNA transfer (Lin et al. 2005).

A fusant strain constructed by Pasha et al. (2007), F11, showed $0.459 \mathrm{~g} \mathrm{~L}^{-1}$ ethanol yield with $90 \%$ fermentation efficiency. In a separate study (Krishnamoorthy et al. 2010), fused $S$. cerevisiae and $K$. marxianus and the resultant fusants produced more ethanol than the parent strain (12.5\% from $18.09 \mathrm{~g} \mathrm{~L}^{-1}$ of biomass). Earlier in 1996, Sakanaka et al. (1996) also fused S. cerevisiae and $K$. marxianus. Among the 40 fusants obtained fusant F1 showed better traits than its parental strains in terms of its growth at high temperature and fermentation abilities.

Genome shuffling, on the other hand, is improvised version of protoplast fusion. It involves several rounds of genetic material transfer leading to an improved strain by the end of process with higher xylose utilization and ethanol yields (Bajwa et al. 2010).
A fusant developed by this technique (Zhang and Geng 2012), ScF2, could utilize up to $250 \mathrm{~g} \mathrm{~L}^{-1}$ of xylose and produced ethanol as well. When compared with $P$. stipitis, this fusant was found to be more tolerant towards xylose and showed high ethanol titers. Another fusant CP11 was produced by intergeneric fusion of $S$. cerevisiae and Candida shehatae (Pasha et al. 2007). It was thermostable at $42{ }^{\circ} \mathrm{C}$ and could ferment wood hydrolysates with ethanol yield of $0.459 \pm 0.012 \mathrm{~g} \mathrm{~g}^{-1}$ and $90 \%$ fermentation efficiency. Ability to ferment wood hydrolysates signifies its industrial relevance to ferment lignocellulosic biomass. In another experiment, S. cerevisiae HAU1, an industrial strain possessing all the desired traits for fermentation but lacking killer properties, was fused with the killer strain of $S$. cerevisiae. The resultant strain retained killer properties of S. cerevisiae and could sustain toxic conditions of fermentation on molasses and nutrient recycling (Bajaj and Sharma 2010).

\section{Adaptation}

Exposing strains to various stresses for a long time results in a stress tolerant strain. This is called adaptation of the strain. It is advantageous to follow this strategy when the genes responsible for a stress are unknown. Such as, in case of inhibitor tolerance, the genetics behind this is unclear. Therefore, adaptation under stress conditions is studied, and the tolerant strains are monitored for genetic changes potentially led to adaptability to stress. It involves repeated passaging of the cultures to increasing concentration of inhibitors in lignocellulosic hydrolysates. Selection is done on the basis of 
Table 4 Improvement strategies followed for yeast strains with their respective ethanol yields

\begin{tabular}{|c|c|c|c|c|c|c|}
\hline Yeast strain & $\begin{array}{l}\text { Yeast improvement } \\
\text { strategy }\end{array}$ & Method of cultivation & Sugar concentration & $\begin{array}{l}\text { Ethanol } \\
\text { yield }\left(\mathrm{g} \mathrm{g}^{-1}\right)\end{array}$ & $\begin{array}{l}\text { Ethanol } \\
\text { productivity }\left(\mathrm{g} \mathrm{L}^{-1}\right. \\
\left.\mathrm{h}^{-1}\right)\end{array}$ & Reference \\
\hline S. cerevisiae ScF2 & $\begin{array}{l}\text { Genome shuffling } \\
\text { product }\end{array}$ & Fermentative & $\begin{array}{l}50 \mathrm{~g} \mathrm{~L}^{-1} \text { glucose }+ \\
50 \mathrm{~g} \mathrm{~L}^{-1} \text { xylose }\end{array}$ & 0.40 & NA & $\begin{array}{l}\text { Zhang and Geng } \\
\text { (2012) }\end{array}$ \\
\hline S. cerevisiae A & Industrial strain & $\begin{array}{l}\text { Anaerobic batch } \\
\text { fermentation }\end{array}$ & $\begin{array}{l}50 \mathrm{gL}^{-1} \text { glucose }+ \\
50 \mathrm{gL}^{-1} \text { xylose }\end{array}$ & 0.42 & NA & $\begin{array}{l}\text { Martinez et al. } \\
\text { (2001) }\end{array}$ \\
\hline $\begin{array}{l}\text { S. cerevisiae and } P \text {. } \\
\text { stipitis }\end{array}$ & Co-culture & Fermentative & $\begin{array}{l}30 \mathrm{~g} \mathrm{~L}^{-1} \text { glucose }+ \\
30 \mathrm{gL}^{-1} \text { xylose }\end{array}$ & 0.41 & NA & $\begin{array}{l}\text { Rouhollah et al. } \\
\text { (2007) }\end{array}$ \\
\hline $\begin{array}{l}\text { P. stipitis and } K \text {. } \\
\text { marxianus }\end{array}$ & Co-culture & Fermentative & $\begin{array}{l}30 \mathrm{~g} \mathrm{~L}^{-1} \text { glucose }+ \\
30 \mathrm{~g} \mathrm{~L}^{-1} \text { xylose }\end{array}$ & 0.36 & NA & $\begin{array}{l}\text { Rouhollah et al. } \\
\text { (2007) }\end{array}$ \\
\hline $\begin{array}{l}\text { S. cerevisiae ITV01 and } \\
\text { P. stipits Y-7124 }\end{array}$ & Co-culture & $\begin{array}{l}\text { Aerobic batch } \\
\text { fermentation }\end{array}$ & $\begin{array}{l}75 \mathrm{~g} \mathrm{~L}^{-1} \text { glucose }+ \\
30 \mathrm{~g} \mathrm{~L}^{-1} \text { xylose }\end{array}$ & 0.40 & NA & $\begin{array}{l}\text { Gutiérrez-Rivera } \\
\text { et al. (2012) }\end{array}$ \\
\hline S. cerevisiae Fusant 1 & Protoplast fusant & Fermentative & $\begin{array}{l}30 \mathrm{~g} \mathrm{~L}^{-1} \text { glucose }+ \\
20 \mathrm{~g} \mathrm{~L}^{-1} \text { xylose }\end{array}$ & 0.19 & NA & Yan et al. (2009) \\
\hline S. cerevisiae YD43-4 & Protoplast fusant & Fermentative & $\begin{array}{l}75 \mathrm{~g} \mathrm{~L}^{-1} \text { glucose }+ \\
30 \mathrm{~g} \mathrm{~L}^{-1} \text { xylose }\end{array}$ & 0.35 & NA & $\begin{array}{l}\text { Chmielewska } \\
\text { (2003) }\end{array}$ \\
\hline S. stipitis BCRC21777 & Adaptation & $\begin{array}{l}\text { Adapted to increasing } \\
\text { concentration }\end{array}$ & $\begin{array}{l}\text { Rice straw } \\
\text { hydrolysate }\end{array}$ & NA & 0.44 & $\begin{array}{l}\text { Huang et al. } \\
\text { (2009) }\end{array}$ \\
\hline S. cerevisiae ( $\delta \mathrm{X}-27)$ & Recombinant & Fermentative & NA & 0.35 & NA & Kato et al. (2013) \\
\hline $\begin{array}{l}\text { S. cerevisiae and C. } \\
\text { intermedia }\end{array}$ & $\begin{array}{l}\text { Protoplast fusion } \\
\text { and mutation }\end{array}$ & Fermentative & $\begin{array}{l}10 \mathrm{~g} \mathrm{~L}^{-1} \text { glucose }+ \\
10 \mathrm{~g} \mathrm{~L}^{-1} \text { xylose }\end{array}$ & $\begin{array}{l}0.38 \text { and } \\
0.42\end{array}$ & 0.33 and 0.65 & $\begin{array}{l}\text { Kahar and Tanaka } \\
\text { (2014) }\end{array}$ \\
\hline
\end{tabular}

growth and fermentation traits. Generally, this is applied to recombinant strains (Harner et al. 2015).

However, there are reports of strain improvement in native strains as well. Through adaptation of strains on hydrolysates, cost requirements are reduced as detoxification is not required. Most of the adaptive techniques are employed to generate inhibitor tolerant strains (Zhu et al. 2009; Liu et al. 2004). Another significant application is growth of native strains on xylose to enhance biomass yields (Attfield and Bell, 2006). Table 4 presents different strategies followed to improve strains for cofermentation potential of strains.

Limitations associated with this strategy are (i) it is time consuming and tedious; (ii) the adapted strains need to be screened out, and this requires high throughput screening technology; and (iii) there are very less criteria for the selection of adapted strains.

\section{Conclusions}

Suitability of S. cerevisiaeon commercial scale is broadly known because of its fermentative properties and robustness. Other native pentose fermenting strains have been studied in detail, and their genes have been transferred to Saccharomyces for improvement in xylose fermentation. These involve engineering efforts that have been partially successful in enhancing ethanol yields. But there are constraints associated with these efforts like xylitol accumulation, low xylose fermentation rate, and low ethanol tolerance. Metabolic engineering strategies provide a solution to these limitations. These involve direct or indirect approaches to target single or multiple genes of the metabolic pathways. Among all the metabolic engineering strategies, genetic engineering being the most accurate and appropriate technique results in desired metabolic product within limited time. Besides, for screening the desired clones, simpler methods are also suitable, whereas for other techniques high throughput screening methods are required. But alone this approach cannot generate an improved strain; hence, a combinatorial strategy is required, wherein combination of genetic engineering along with other approaches like adaptation/evolutionary engineering is involved. Furthermore, some uncovered hidden traits of xylose metabolism still need to be revealed to improve the efficacy of co-fermentation processes. This could be done by involving random metabolic approaches as there are several metabolic pathways connected with xylose metabolism, and targeting each pathway is a tedious task. On the other hand, random approaches can alter the flow of the pathways which can later be studied to understand the genetics involved in the improvement strategies.

\footnotetext{
Acknowledgements

Authors are also grateful to the Director, ICAR-Indian Agricultural Research Institute, New Delhi, for giving us this platform to conduct research activities. We also acknowledge ICAR-AMAAS (12-124) for providing funds.
}

\section{Research involving human participants and/or animals N/A}

\section{Authors' contributions}

SS and AA both conceptualized the idea and wrote the review article. The authors read and approved the final manuscript. 


\section{Funding}

We are thankful to ICAR-AMAAS (12-124) for providing funds.

\section{Availability of data and materials}

Data sharing is not applicable to this article as no datasets were generated or analyzed during the current study.

\section{Ethics approval and consent to participate}

Not applicable

\section{Consent for publication}

Not applicable

\section{Competing interests}

Authors declare no competing interests.

\section{Received: 3 December 2019 Accepted: 8 July 2020}

Published online: 07 August 2020

\section{References}

Abdullah B, Muhammad SA, Shokravi Z, Ismail S, Kassim KA, Mahmood AN et al (2019) Fourth generation biofuel: a review on risks and mitigation strategies Renew Sust Energ Rev 1;107:37-50

Ai P, Zhang X, Dinamarca C, Elsayed M, Yu L, Xi J et al (2019) Different effects of ozone and aqueous ammonia in a combined pretreatment method on rice straw and dairy manure fiber for enhancing biomethane production. Biores technol 1;282:275-84.

Albergaria H, Arneborg N (2016) Dominance of Saccharomyces cerevisiae in alcoholic fermentation processes: role of physiological fitness and microbial interactions. Appl Microbiol Biotechnol 1;100(5):2035-46.

Almeida JR, Runquist D, SànchezNogué V, Lidén G, Gorwa-Grauslund MF (2011) Stress-related challenges in pentose fermentation to ethanol by the yeast Saccharomyces cerevisiae. Biotechnol J6(3):286-299

Amore R, Kötter P, Küster C, Ciriacy M, Hollenberg CP (1991) Cloning and expression in Saccharomyces cerevisiae of the NAD (P) H-dependent xylose reductase-encoding gene (XYL1) from the xylose-assimilating yeast Pichia stipitis. Gene 109(1):89-97

Anjos J, de Sousa HR, Roca C, Cássio F, Luttik M, Pronk JT et al (2013) Fsy1, the sole hexose-proton transporter characterized in Saccharomyces yeasts, exhibits a variable fructose: $\mathrm{H}+$ stoichiometry. Biochim Biophys Acta Biomembr1;1828(2):201-7

Attfield PV, Bell PJ (2006) Use of population genetics to derive non-recombinant Saccharomyces cerevisiae strains that grow using xylose as a sole carbon source. FEMS Yeast Res 1;6(6):862-8

Bailey JE (1991) Toward a science of metabolic engineering. Science 21; 252(5013):1668-75.

Bajaj BK, Sharma S (2010) Construction of killer industrial yeast Saccharomyces cerevisiae HAU-1 and its fermentation performance. Braz J Microbiol 41(2): 477-485

Bajwa PK, Pinel D, Martin VJ, Trevors JT, Lee H (2010) Strain improvement of the pentose-fermenting yeast Pichia stipitis by genome shuffling. J Microbiol Methods1;81(2):179-86.

Bao X, Gao D, Qu Y, Wang Z, Walfridssion M, Hahn-Hagerbal B (1997) Effect on product formation in recombinant Saccharomyces cerevisiae strains expressing different levels of xylose metabolic genes. Chin J Biotechnol 13(4): 225-231

Bao Z, Xiao H, Liang J, Zhang L, Xiong X, Sun N et al (2014) Homology-integrated CRISPR-Cas (HI-CRISPR) system for one-step multigenedisruption in Saccharomyces cerevisiae. ACS Synth Biol 19;4(5):585-94.

Belisa B, Scheid B, Gonçalves DL, Knychala MM, Matsushika A, Bon EP et al (2015) Cloning novel sugar transporters from Scheffersomyces (Pichia) stipitis allowing $\mathrm{d}$-xylose fermentation by recombinant Saccharomyces cerevisiae. Biotechnol Lett 1;37(10):1973-82.

Chandel AK, Singh OV, Rao LV, Chandrasekhar G, Narasu ML (2011) Bioconversion of novel substrate Saccharum spontaneum, a weedy material, into ethanol by Pichia stipitis NCIM3498. Bioresour Technol 1;102(2):1709-14.

Chen Y, Wu Y, Zhu B, Zhang G, Wei N (2018) Co-fermentation of cellobiose and xylose by mixed culture of recombinant Saccharomyces cerevisiae and kinetic modeling. Plos One. 25;13(6):e0199104
Chmielewska J (2003) Selected biotechnological features of hybrids of Saccharomyces cerevisiae and Yamadazyma stipitis. Electronic Journal of Poland Agricultural University of Biotechnology 6:1-13

Chu BC, Lee H (2007) Genetic improvement of Saccharomyces cerevisiae for xylose fermentation. Biotechnol Adv. 1;25(5):425-41.

Colabardini AC, Ries LN, Brown NA, Dos Reis TF, Savoldi M, Goldman MH, Menino JF, Rodrigues F, Goldman GH (2014) Functional characterization of a xylose transporter in Aspergillus nidulans. Biotechnol Biofuel 7(1):46

Cong L, Ran FA, Cox D, Lin S, Barretto R, Habib N et al (2013) Multiplex genome engineering using CRISPR/Cas systems. Science 15;339(6121):819-23.

de Figueiredo Vilela L, de Araujo VP, de Sousa Paredes R, da Silva Bon EP, Torres FA, Neves BC et al (2015) Enhanced xylose fermentation and ethanol production by engineered Saccharomyces cerevisiae strain. AMB Express1;5(1):16.

Demeke MM, Dietz H, Li Y, Foulquié-Moreno MR, Mutturi S, Deprez S, Den Abt T et al (2013) Development of a D-xylose fermenting and inhibitor tolerant industrial Saccharomyces cerevisiae strain with high performance in lignocellulose hydrolysates using metabolic and evolutionary engineering. Biotechnol Biofuels 6(1):89

Dien BS, Cotta MA, Jeffries TW (2003) Bacteria engineered for fuel ethanol production: current status. Appl Microbiol Biotechnol 1;63(3):258-66.

Dmytruk OV, Dmytruk KV, Voronovsky AY, Sibirny AA (2008) Metabolic engineering of the initial stages of xylose catabolism in yeast for the purpose of constructing efficient producers of ethanol from lignocellulosics. Cytol Genet 1;42(2):127-38.

Does AL, Bisson LF (1989) Characterization of xylose uptake in the yeasts Pichia heedii and Pichia stipitis. Appl. Environ. Microbiol1;55(1):159-64.

Eliasson A, Hofmeyr JH, Pedler S, Hahn-Hägerdal B (2001) The xylose reductase/ xylitol dehydrogenase/xylulokinase ratio affects product formation in recombinant xylose-utilising Saccharomyces cerevisiae. Enzyme Microb Technol 5;29(4-5):288-97.

Elsayed M, Abomohra AE, Ai P, Jin K, Fan Q, Zhang Y (2019) Acetogenesis and methanogenesis liquid digestates for pretreatment of rice straw: a holistic approach for efficient biomethane production and nutrient recycling. Energ Convers Manag 1;195:447-56.

Elsayed M, Abomohra AE, Ai P, Wang D, El-Mashad HM, Zhang Y (2018) Biorefining of rice straw by sequential fermentation and anaerobic digestion for bioethanol and/or biomethane production: comparison of structural properties and energy output. Biores technol 2018 1;268:183-9.

Erdei B, Barta Z, Sipos B, Réczey K, Galbe M, Zacchi G (2010) Ethanol production from mixtures of wheat straw and wheat meal. Biotechnol Biofuels3(1):16.

Fonseca C, Spencer-Martins I, Hahn-Hägerdal B (2007) L-arabinose metabolism in Candida arabinofermentans PYCC 5603 T and Pichia guilliermondii PYCC 3012: influence of sugar and oxygen on product formation. Appl Microbiol Biotechnol 1;75(2):303-10.

Gárdonyi M, Jeppsson M, Lidén G, Gorwa-Grauslund MF, Hahn-Hägerdal B (2003) Control of xylose consumption by xylose transport in recombinant Saccharomyces cerevisiae. Biotechnol Bioeng 30;82(7):818-24.

Gong CS, Chen LF, Flickinger MC, Chiang LC, Tsao GT (1981) Production of ethanol from D-xylose by using D-xylose isomerase and yeasts. Appl Environ Microbiol 1;41(2):430-6.

Gutiérrez-Rivera B, Waliszewski-Kubiak K, Carvajal-Zarrabal O, Aguilar-Uscanga MG (2012) Conversion efficiency of glucose/xylose mixtures for ethanol production using Saccharomyces cerevisiae ITV01 and Pichia stipitis NRRL Y7124. J Chem Technol Biotechnol 1;87(2):263-70.

Hahn-Hägerdal B, Wahlbom CF, Gárdonyi M, van Zyl WH, Otero RR, Jönsson L (2001) Metabolic engineering of Saccharomyces cerevisiae for xylose utilization. InMetabol Eng (pp. 53-84). Springer, Berlin, Heidelberg.

Hara KY, Kobayashi J, Yamada R, Sasaki D, Kuriya Y, Hirono-Hara Y et al (2017) Transporter engineering in biomass utilization by yeast. FEMS Yeast Res 1 17(7).

Harner NK, Wen X, Bajwa PK, Austin GD, Ho CY, Habash MB et al (2015) Genetic improvement of native xylose-fermenting yeasts for ethanol production. J Ind Microbiol Biotechnol1;42(1):1-20

Hector RE, Mertens JA, Bowman MJ, Nichols NN, Cotta MA, Hughes SR (2011)Saccharomyces cerevisiae engineered for xylose metabolism requires gluconeogenesis and the oxidative branch of the pentose phosphate pathway for aerobic xylose assimilation. Yeast1;28(9):645-60.

Heluane H, Spencer JF, Spencer D, De Figueroa L, Callieri DA (1993) Characterization of hybrids obtained by protoplast fusion, between Pachysolentannophilus and Saccharomyces cerevisiae. Appl Microbiol Biotechnol 1;40(1):98-100. 
Ho NW, Chen Z, Brainard AP (1998) Genetically engineered Saccharomyces yeast capable of effective cofermentation of glucose and xylose. Appl Environ Microbiol 1;64(5):1852-9.

Hou X (2012) Anaerobic xylose fermentation by Spathasporapassalidarum. Appl Microbiol Biotechnol1;94(1):205-14.

Huang CF, Lin TH, Guo GL, Hwang WS (2009) Enhanced ethanol production by fermentation of rice straw hydrolysate without detoxification using a newly adapted strain of Pichia stipitis. Bioresour Technol 1;100(17):3914-20.

Ismail KS, Sakamoto T, Hatanaka H, Hasunuma T, Kondo A (2013) Gene expression cross-profiling in genetically modified industrial Saccharomyces cerevisiae strains during high-temperature ethanol production from xylose. Biotechnol10;163(1):50-60.

Jansen ML, Bracher JM, Papapetridis I, Verhoeven MD, de Bruijn H, de Waal PP et al (2017) Saccharomyces cerevisiae strains for second-generation ethanol production: from academic exploration to industrial implementation. FEMS Yeast Res 1:17(5)

Jeffries TW (1983) Utilization of xylose by bacteria, yeasts, and fungi. In Pentoses and lignin (pp. 1-32). Springer, Berlin, Heidelberg.

Jeffries TW(1985) Emerging technology for fermenting D-xylose. Trends Biotechnol 1;3(8):208-12.

Jeffries TW, Van Vleet JR (2009) Pichia stipitis genomics, transcriptomics, and gene clusters. FEMS Yeast Res. 1;9(6):793-807.

Jeppsson M, Johansson B, Jensen PR, Hahn-Hägerdal B, Gorwa-Grauslund MF (2003) The level of glucose-6-phosphate dehydrogenase activity strongly influences xylose fermentation and inhibitor sensitivity in recombinant Saccharomyces cerevisiae strains. Yeast20(15):1263-72.

Jin YS, Alper H, Yang YT, Stephanopoulos G (2005) Improvement of xylose uptake and ethanol production in recombinant Saccharomyces cerevisiae through an inverse metabolic engineering approach. Appl Environ Microbiol1;71(12): 8249-56.

Jin YS, Jeffries TW (2003) Changing flux of xylose metabolites by altering expression of xylose reductase and xylitol dehydrogenase in recombinant Saccharomyces cerevisiae. InBiotechnology for fuels and chemicals (pp. 277285). Humana Press, Totowa, NJ.

Jin YS, Jeffries TW (2004) Stoichiometric network constraints on xylose metabolism by recombinant Saccharomyces cerevisiae. Metabol Eng1;6(3):229-38.

Jin YS, Laplaza JM, Jeffries TW (2004) Saccharomyces cerevisiae engineered for xylose metabolism exhibits a respiratory response. Appl Environ Microbiol 1 70(11):6816-25.

Kahar P, Tanaka S (2014) A xylose-fermenting yeast hybridized by intergeneric fusion between Saccharomyces cerevisiae and Candida intermedia mutants for ethanol production. Sustain Chem Process 1;2(1):17.

Karhumaa K, Fromanger R, Hahn-Hägerdal B, Gorwa-Grauslund MF (2007a) High activity of xylose reductase and xylitol dehydrogenase improves xylose fermentation by recombinant Saccharomyces cerevisiae. Appl Microbiol Biotechnol 1;73(5):1039-46.

Karhumaa K, Hahn-Hägerdal B, Gorwa-Grauslund MF (2005) Investigation of limiting metabolic steps in the utilization of xylose by recombinant Saccharomyces cerevisiae using metabolic engineering. Yeast 15;22(5):359-68.

Karhumaa K, Sanchez RG, Hahn-Hägerdal B, Gorwa-Grauslund MF (2007b) Comparison of the xylose reductase-xylitol dehydrogenase and the xylose isomerase pathways for xylose fermentation by recombinant Saccharomyces cerevisiae. Microb Cell Fact 1;6(1):5.

Karimi K, Kheradmandinia S, Taherzadeh MJ (2006) Conversion of rice straw to sugars by dilute-acid hydrolysis. Biomass Bioenergy 1;30(3):247-53.

Katahira S, Ito M, Takema H, Fujita Y, Tanino T, Tanaka T, Fukuda H, Kondo A (2008) Improvement of ethanol productivity during xylose and glucose cofermentation by xylose-assimilating S. cerevisiae via expression of glucose transporter Sut1. Enz Microb Technol 43(2):115-119

Kato H, Matsuda F, Yamada R, Nagata K, Shirai T, Hasunuma T et al (2013) Cocktail $\delta$ integration of xylose assimilation genes for efficient ethanol production from xylose in Saccharomyces cerevisiae. J Biosci Bioeng 1;116(3):333-6.

Khattab SM, Watanabe S, Saimura M, Kodaki T (2011) A novel strictly NADPHdependent Pichia stipitis xylose reductase constructed by site-directed mutagenesis. Biochem Biophys Res Commun 14;404(2):634-7.

Kilian SG, Van Uden N (1988) Transport of xylose and glucose in the xylosefermenting yeast Pichiastipitis. Appl Microbiol Biotechnol1;27(5-6):545-8.

Kim SR, Kwee NR, Kim H, Jin YS (2013a) Feasibility of xylose fermentation by engineered Saccharomyces cerevisiae overexpressing endogenous aldose reductase (GRE3), xylitol dehydrogenase (XYL2), and xylulokinase (XYL3) from Scheffersomyces stipitis. FEMS Yeast Res 1;13(3):312-21.
Kim SR, Skerker JM, Kang W, Lesmana A, Wei N, Arkin AP, Jin YS (2013b) Rational and evolutionary engineering approaches uncover a small set of genetic changes efficient for rapid xylose fermentation in Saccharomyces cerevisiae. PloS One 8(2)

Kim SR, Xu H, Lesmana A, Kuzmanovic U, Au M, Florencia C et al (2015) Deletion of $\mathrm{PHO13}$, encoding haloaciddehalogenase type IIA phosphatase, results in upregulation of the pentose phosphate pathway in Saccharomyces cerevisiae. Appl Environ Microbiol 1;81(5):1601-9.

Kobayashi Y, Sahara T, Ohgiya S, Kamagata Y, Fujimori KE (2018) Systematic optimization of gene expression of pentose phosphate pathway enhances ethanol production from a glucose/xylose mixed medium in a recombinant Saccharomyces cerevisiae. AMB Express 1;8(1):139.

Kobayashi Y, Sahara T, Suzuki T, Kamachi S, Matsushika A, Hoshino T et al (2017) Genetic improvement of xylose metabolism by enhancing the expression of pentose phosphate pathway genes in Saccharomyces cerevisiae IR-2 for hightemperature ethanol production. J Ind Microbiol Biotechnol 1;44(6):879-91.

Koppram R, Albers E, Olsson L (2012) Evolutionary engineering strategies to enhance tolerance of xylose utilizing recombinant yeast to inhibitors derived from spruce biomass. Biotechnol Biofuel 1:32

Kostrzynska M, Sopher CR, Lee H (1998) Mutational analysis of the role of the conserved lysine-270 in the Pichia stipitis xylose reductase. FEMS Microbiol letters 1;159(1):107-12.

Kötter P, Ciriacy M (1993) Xylose fermentation by Saccharomyces cerevisiae. Applied microbiology and biotechnology. 1993 Mar 1;38(6):776-783.

Kötter P, Amore R, Hollenberg CP, Ciriacy M (1990) Isolation and characterization of the Pichia stipitis xylitol dehydrogenase gene, XYL2, and construction of a xyloseutilizing Saccharomyces cerevisiae transformant. Curr Genet 1;18(6):493-500.

Latimer LN, Dueber JE (2017) Iterative optimization of xylose catabolism in Saccharomyces cerevisiae using combinatorial expression tuning. Biotechnol Bioeng 114(6):1301-1309

Leandro MJ, Gonçalves P, Spencer-Martins I (2006) Two glucose/xylose transporter genes from the yeast Candida intermedia: first molecular characterization of a yeast xylose-H+ symporter. Biochem J 1;395(3):543-9.

Lee J (1997) Biological conversion of lignocellulosic biomass to ethanol. J Biotechnol. 23;56(1):1-24.

Lee SK, Chou H, Ham TS, Lee TS, Keasling JD (2008) Metabolic engineering of microorganisms for biofuels production: from bugs to synthetic biology to fuels. Curr Opin Biotechnol 1;19(6):556-63.

Lee SY (2012) Metabolic engineering and synthetic biology in strain development 491-2.

Li H, Schmitz O, Alper HS (2016) Enabling glucose/xylose co-transport in yeast through the directed evolution of a sugar transporter. Appl Microbiol Biotechnol 1;100(23):10215-23.

Li YC, Gou ZX, Liu ZS, Tang YQ, Akamatsu T, Kida K (2014) Synergistic effects of TAL1 over-expression and PHO13 deletion on the weak acid inhibition of xylose fermentation by industrial Saccharomyces cerevisiae strain. Biotechnol Lett 1;36(10):2011-21.

Lin CC, Hsieh PC, Mau JL, Teng DF (2005) Construction of an intergeneric fusion from SchizoSaccharomyces pombe and Lentinula edodes for xylan degradation and polyol production. Enzyme Microb Technol 6;36(1):107-17.

Lindqvist Y, Schneider G, Ermler U, Sundström M (1992) Three-dimensional structure of transketolase, a thiamine diphosphate dependent enzyme, at 2.5 A resolution. EMBO J 11(7):2373-2379

Liu ZL, Slininger PJ, Dien BS, Berhow MA, Kurtzman CP, Gorsich SW (2004) Adaptive response of yeasts to furfural and 5-hydroxymethylfurfural and new chemical evidence for HMF conversion to 2, 5-bis-hydroxymethylfuran. J Ind Microbiol Biotechnol 1;31(8):345-52.

Liu ZL, Slininger PJ, Gorsich SW (2005) Enhanced biotransformation of furfural and hydroxymethylfurfural by newly developed ethanologenic yeast strains. Appl Biochem Biotechnol 121(1-3):451-460

Lucas C, Van Uden N (1986) Transport of hemicellulose monomers in the xylosefermenting yeast Candida shehatae. Appl Microbiol Biotechnol1;23(6):491-5.

Maleszka R, Schneider H (1982a) Fermentation of D-xylose, xylitol, and D-xylulose by yeasts. Can J Microbiol 1;28(3):360-3.

Maleszka R, Schneider H (1982b) Concurrent production and consumption of ethanol by cultures of Pachysolentannophilus growing on D-xylose. Appl. Environ. Microbiol1;44(4):909-12.

Martín C, Marcet M, Almazán O, Jönsson L (2007) Adaptation of a recombinant xylose-utilizing Saccharomyces cerevisiae strain to a sugarcane bagasse hydrolysate with high content of fermentation inhibitors. Bioresour Technol 1;98(9):1767-73. 
Martinez A, Rodriguez ME, Wells ML, York SW, Preston JF, Ingram LO (2001) Detoxification of dilute acid hydrolysates of lignocellulose with lime. Biotechnol Prog 17(2):287-293

Matsushika A, Goshima T, Fujii T, Inoue H, Sawayama S, Yano S (2012) Characterization of non-oxidative transaldolase and transketolase enzymes in the pentose phosphate pathway with regard to xylose utilization by recombinant Saccharomyces cerevisiae. Enzyme Microb Technol 10;51(1):16-25.

Matsushika A, Inoue H, Watanabe S, Kodaki T, Makino K, Sawayama S (2009) Efficient bioethanol production by a recombinant flocculent Saccharomyces cerevisiae strain with a genome-integrated NADP+-dependent xylitol dehydrogenase gene. Appl Environ Microbiol 1;75(11):3818-22.

Matsushika A, Sawayama S (2008) Efficient bioethanol production from xylose by recombinant Saccharomyces cerevisiae requires high activity of xylose reductase and moderate xylulokinase activity. J Biosci Bioeng 1;106(3):306-9.

Matsushika A, Watanabe S, Kodaki T, Makino K, Sawayama S (2008) Bioethanol production from xylose by recombinant Saccharomyces cerevisiae expressing xylose reductase, NADP+-dependent xylitol dehydrogenase, and xylulokinase. J Biosci Bioeng 1;105(3):296-9.

McMillan JD (1993) Xylose fermentation to ethanol: a review(No. NREL/TP-421-4944). National Renewable Energy Lab., Golden, CO (United States).

Meinander NQ, Hahn-Hagerdal B (1997) Fed-batch xylitol production with two recombinant Saccharomyces cerevisiae strains expressing XYL1 at different levels, using glucose as a cosubstrate: a comparison of production parameters and strain stability. Biotechnoi. Bioeng. 54:391-99.

Meinander NQ, Boels I, Hahn-Hägerdal B (1999) Fermentation of xylose/glucose mixtures by metabolically engineered Saccharomyces cerevisiae strains expressing XYL1 and XYL2 from Pichia stipitis with and without overexpression of TAL1. Biores Technol 1;68(1):79-87.

Metzger MH, Hollenberg CP (1994) Isolation and characterization of the Pichia stipitis transketolase gene and expression in a xylose-utilising Saccharomyces cerevisiae transformant. Appl Microbiol Biotechnol 1;42(2-3):319-25.

Metzger MH, Hollenberg CP (1995) Amino acid substitutions in the yeast Pichia stipitis xylitol dehydrogenase coenzyme-binding domain affect the coenzyme specificity. Eur J Biochem 228(1):50-54

Millati R, Niklasson C, Taherzadeh MJ (2002) Effect of pH, time and temperature of overliming on detoxification of dilute-acid hydrolyzates for fermentation by Saccharomyces cerevisiae. Process Biochem 2;38(4):515-22.

Miller RG, Sorrell SR (2014) Introduction: the future of oil supply. Philosophical Transactions: Mathematical, Physical and Engineering Sciences. 13:1-27

Miosga T, Zimmermann FK (1996) Cloning and characterization of the first two genes of the non-oxidative part of the Saccharomyces cerevisiae pentosephosphate pathway. Curr Genet 1;30(5):404-9.

Mishra P, Singh A (1993) Microbial pentose utilization. Adv Appl Microbiol 1 (Vol. 39, pp. 91-152). Academic Press

Mobini-Dehkordi M, Nahvi I, Zarkesh-Esfahani H, Ghaedi K, Tavassoli M, Akada R (2008) Isolation of a novel mutant strain of Saccharomyces cerevisiae by an ethyl methane sulfonate-induced mutagenesis approach as a high producer of bioethanol. J Biosci Bioeng 105(4):403-408

Moysés D, Reis V, Almeida J, Moraes L, Torres F (2016) Xylose fermentation by Saccharomyces cerevisiae: challenges and prospects. Int J Mol Sci 17(3):207

Nevoigt E (2008) Progress in metabolic engineering of Saccharomyces cerevisiae. Microbiol Mol Biol Rev 1;72(3):379-412.

$\mathrm{Ni}$ H, Laplaza JM, Jeffries TW (2007) Transposon mutagenesis to improve the growth of recombinant Saccharomyces cerevisiae on D-xylose. Appl Environ Microbiol 1;73(7):2061-6.

Osiro KO, Borgström C, Brink DP, Fjölnisdóttir BL, Gorwa-Grauslund MF (2019) Exploring the xylose paradox in Saccharomyces cerevisiae through in vivo sugar signalomics of targeted deletants. Microb Cell Fact 18(1):88

Ostergaard S, Olsson L, Nielsen J (2000) Metabolic engineering of Saccharomyces cerevisiae. Microbiol Mol Biol Rev 1;64(1):34-50.

Overkamp KM, Bakker BM, Kötter P, Luttik MA, van Dijken JP, Pronk JT (2002) Metabolic engineering of glycerol production in Saccharomyces cerevisiae. Appl Environ Microbiol 1;68(6):2814-21.

Parajó JC, Domínguez H, Domínguez JM (1996) Charcoal adsorption of wood hydrolysates for improving their fermentability: influence of the operational conditions. Bioresour Technol 1;57(2):179-85.

Pasha C, Kuhad RC, Rao LV (2007) Strain improvement of thermotolerant Saccharomyces cerevisiae VS3 strain for better utilization of lignocellulosic substrates. J Appl Microbiol 103(5):1480-1489
Petschacher B, Nidetzky B (2005) Engineering Candida tenuis xylose reductase for improved utilization of NADH: antagonistic effects of multiple side chain replacements and performance of site-directed mutants under simulated in vivo conditions. Appl Environ Microbiol 1;71(10):6390-3.

Robak K, Balcerek M (2018) Review of second generation bioethanol production from residual biomass. Food Technol Biotech. 56(2):174

Roca C, Nielsen J, Olsson L (2003) Metabolic engineering of ammonium assimilation in xylose-fermenting Saccharomyces cerevisiae improves ethanol production. Appl Environ Microbiol 1;69(8):4732-6.

Rodriguez-Peña JM, Cid VJ, Arroyo J, Nombela C (1998) The YGR194c (XKS1) gene encodes the xylulokinase from the budding yeast Saccharomyces cerevisiae. FEMS Microbiol Lett 1;162(1):155-60.

Rouhollah H, Iraj N, Giti E, Sorah A (2007) Mixed sugar fermentation by Pichiastipitis, Sacharomyces cerevisiae, and an isolated xylose fermenting Kluyveromyces marxianus and their cocultures. African J Biotechnol6(9).

Runquist D, Fonseca C, Rådström P, Spencer-Martins I, Hahn-Hägerdal B (2009) Expression of the Gxf1 transporter from Candida intermedia improves fermentation performance in recombinant xylose-utilizing Saccharomyces cerevisiae. Appl Microbiol Biotechnol 1;82(1):123-30.

Sakanaka K, Yan W, Kishida M, Sakai T (1996) Breeding a fermentative yeast at high temperature using protoplast fusion. J Ferment Bioengineer 81(2):104-108

Sarkar N, Ghosh SK, Bannerjee S, Aikat K (2012) Bioethanol production from agricultural wastes: an overview. Renew Energ 1;37(1):19-27.

Sauer U (2001) Evolutionary engineering of industrially important microbial phenotypes. In Metabol Eng (pp. 129-169). Springer, Berlin, Heidelberg.

Sauer U, Schlattner U (2004) Inverse metabolic engineering with phosphagen kinase systems improves the cellular energy state. Metabol Eng 1;6(3):220-8.

Selim K, El-Ghwas D, Easa S, Abdelwahab Hassan M (2018) Bioethanol a microbial biofuel metabolite; new insights of yeasts metabolic engineering. Fermentation 4(1):16

Sharma S, Sharma S, Singh S, Arora A (2016) Improving yeast strains for pentose hexose co-fermentation: successes and hurdles. InProceedings of the First International Conference on Recent Advances in Bioenergy Research (pp. 2341). Springer, New Delhi.

Shi J, Zhang M, Zhang L, Wang P, Jiang L, Deng H (2014) Xylose-fermenting Pichia stipitis by genome shuffling for improved ethanol production. Microb Biotechnol 7(2):90-99

Shin HY, Nijland JG, de Waal PP, Driessen AJM (2017) The amino-terminal tail of Hxt11 confers membrane stability to the Hxt2 sugar transporter and improves xylose fermentation in the presence of acetic acid. Biotechnol Bioeng 9999:1-9.

Skoog K, Hahn-Hägerdal B (1990) Effect of oxygenation on xylose fermentation by Pichia stipitis. Appl Environ Microbiol1;56(11):3389-94.

Slininger PJ, Bothast RJ, Van Cauwenberge JE, Kurtzman CP (1982) Conversion of D-xylose to ethanol by the yeast Pachysolen tannophilus. Biotechnol Bioeng 24(2):371-384

Sonderegger M, Sauer U (2003) Evolutionary engineering of Saccharomyces cerevisiae for anaerobic growth on xylose. Appl Environ Microbiol 1;69(4): 1990-8.

Sonderegger M, Schümperli M, Sauer U (2004) Metabolic engineering of a phosphoketolase pathway for pentose catabolism in Saccharomyces cerevisiae. Appl Environ Microbiol 1;70(5):2892-7.

Stephanopoulos $G$ (2007) Challenges in engineering microbes for biofuels production. Science 9;315(5813):801-4.

Tabah B, Pulidindi IN, Chitturi VR, Arava LM, Varvak A, Foran E et al (2017) Solarenergy-driven conversion of biomass to bioethanol: a sustainable approach. J Mater Chem A 5(30):15486-15506

Tantirungkij M, Izuishi T, Seki T, Yoshida T (1994) Fed-batch fermentation of xylose by a fast-growing mutant of xylose-assimilating recombinant Saccharomyces cerevisiae. Appl Microbiol Biotechnol 1;41(1):8-12.

Tantirungkij M, Nakashima N, Seki T, Yoshida T (1993) Construction of xyloseassimilating Saccharomyces cerevisiae. J Biosci Bioeng 1;75(2):83-8.

Toivari MH, Aristidou A, Ruohonen L, Penttilä M (2001) Conversion of xylose to ethanol by recombinant Saccharomyces cerevisiae: importance of xylulokinase (XKS1) and oxygen availability. Metabol Eng 1;3(3):236-49.

Toivari MH, Salusjärvi L, Ruohonen L, Penttilä M (2004) Endogenous xylose pathway in Saccharomyces cerevisiae. Appl Environ Microbiol 1;70(6):3681-6.

Van Vleet JH, Jeffries TW (2009) Yeast metabolic engineering for hemicellulosic ethanol production. Curr Opin Biotechnol 1;20(3):300-6.

Walfridsson M, Anderlund M, Bao X, Hahn-Hägerdal B (1997) Expression of different levels of enzymes from the Pichiastipitis XYL1 and XYL2 genes in 
Saccharomyces cerevisiae and its effects on product formation during xylose utilisation. Appl Microbiol Biotechnol1;48(2):218-24.

Walfridsson M, Hallborn J, Penttilä ME, Keränen SI, Hahn-Hägerdal B (1995) Xylose-metabolizing Saccharomyces cerevisiae strains overexpressing the TKL1 and TAL1 genes encoding the pentose phosphate pathway enzymes transketolase and transaldolase. Appl Environ Microbiol 1;61(12):4184-90.

Wang T, Nolte MW, Shanks BH (2014) Catalytic dehydration of C 6 carbohydrates for the production of hydroxymethylfurfural (HMF) as a versatile platform chemical. Green Chem. 16(2):548-572

Watanabe S, Kodaki T, Makino K (2005) Complete reversal of coenzyme specificity of xylitol dehydrogenase and increase of thermostability by the introduction of structural zinc. J Biol Chem18;280(11):10340-9.

Watanabe S, Saleh AA, Pack SP, Annaluru N, Kodaki T, Makino K (2007) Ethanol production from xylose by recombinant Saccharomyces cerevisiae expressing protein-engineered NADH-preferring xylose reductase from Pichia stipitis. Microbiol1;153(9):3044-54.

Webb SR, Lee H (1990) Regulation of D-xylose utilization by hexoses in pentosefermenting yeasts. Biotechnol Adv 1;8(4):685-97.

Wei N, Oh EJ, Million G, Cate JHD, Jin Y-S (2015) Simultaneous utilization of cellobiose, xylose, and acetic acid from lignocellulosic biomass for biofuel production by an engineered yeast platform. ACS Synth Biol

Xu H, Kim S, Sorek H, Lee Y, Jeong D, Kim J et al (2016) PHO13 deletion-induced transcriptional activation prevents sedoheptulose accumulation during xylose metabolism in engineered Saccharomyces cerevisiae. Metab Eng 1;34:88-96.

Yan F, Bai F, Tian S, Zhang J, Zhang Z, Yang X (2009) Strain construction for ethanol production from dilute-acid lignocellulosichydrolysate. Appl Biochem Biotechnol 1;157(3):473-82

Zhang W, Geng A (2012) Improved ethanol production by a xylose-fermenting recombinant yeast strain constructed through a modified genome shuffling method. Biotechnol Biofuels 5(1):46

Zheng DQ, Wu XC, Wang PM, Chi XQ, Tao XL, Li P, Jiang XH, Zhao YH (2011) Drug resistance marker-aided genome shuffling to improve acetic acid tolerance in Saccharomyces cerevisiae. J Ind Microbiol Biotechnol 38(3):415-422

Zhu JJ, Yong Q, Xu Y, Chen SX, Yu SY (2009) Adaptation fermentation of Pichia stipitis and combination detoxification on steam exploded lignocellulosic prehydrolyzate. Natural Science30;1(01):47.

\section{Publisher's Note}

Springer Nature remains neutral with regard to jurisdictional claims in published maps and institutional affiliations.

Ready to submit your research? Choose BMC and benefit from:

- fast, convenient online submission

- thorough peer review by experienced researchers in your field

- rapid publication on acceptance

- support for research data, including large and complex data types

- gold Open Access which fosters wider collaboration and increased citations

- maximum visibility for your research: over $100 \mathrm{M}$ website views per year

At $\mathrm{BMC}$, research is always in progress.

Learn more biomedcentral.com/submissions 